\title{
OCORRÊNCIA DE VIOLÊNCIA INTRAFAMILIAR RELACIONADA AO CONSUMO DE ÁLCOOL E OUTRAS DROGAS NO BRASIL
}

\author{
LUÍS PAULO SOUZA E SOUZA \\ Enfermeiro graduado pela Universidade Estadual de Montes Claros (UNIMONTES). Atuou como Residente em Saúde \\ Cardiovascular no Hospital das Clínicas da Universidade Federal de Minas Gerais (UFMG). Mestre em Enfermagem pela \\ UFMG; Doutor em Saúde Pública pela UFMG; Pós-Doutorado em Educação (Educação em Saúde) pela Universidade do \\ Estado do Pará (UEPA) e em Desenvolvimento Regional pela Universidade de Santa Cruz do Sul (UNISC). \\ País: Brasil Estado: Amazonas Cidade: Manaus \\ Email de contato: luis.pauloss12@gmail.com ORCID: https://orcid.org/0000-0002-9801-4157
}

\section{GRAZIELLE NEVES SOARES}

Possui graduação em Enfermagem pela Universidade Federal de Minas Gerais (2007). Especialista em Saúde da Família e Comunidade pela UFMG. Atualmente trabalha no Serviço Atendimento Médico de Urgência (SAMU-USA 03) e na Atenção Primária (Centro de Saúde Jardim Alvorada) ambos da Prefeitura Municipal de Belo Horizonte. Cursando Especialização em Atenção em Álcool e Drogas na Escola de Saúde Pública de Minas Gerais.

País: Brasil Estado: Minas Gerais Cidade: Belo Horizonte

\section{MARCONI MOURA FERNANDES}

Possui graduação em Psicologia pela Pontifícia Universidade Católica de Minas Gerais (2010); Pós graduação em Análise Institucional, Esquizoanálise e Esquizodrama: Clínica de Indivíduos, Grupos, Organizações e Redes Sociais pela Inst. Félix Guattari / Fund. Gregório Baremblitt (2012); e Mestrado em Enfermagem na linha de pesquisa educação em saúde pela Escola de Enfermagem da Universidade Federal de Minas Gerais (2016). Tem experiência nas áreas de psicologia clínica; análise institucional de grupos, instituições e movimentos sociais; educação; ética e pesquisa clínica em saúde; políticas públicas de saúde; promoção da saúde; reforma psiquiátrica e luta antimanicomial.

País: Brasil Estado: Minas Gerais Cidade: Belo Horizonte

\section{ALINE MARIA FIGUEIREDO KO DA CUNHA}

Possui graduação em Psicologia pela Pontifícia Universidade Católica de Minas Gerais (2006) e especializações em Educação na Saúde para Preceptores do SUS (2014) e em Atenção a Usuários de Drogas no SUS (2019). Tem experiência na área de Psicologia, com ênfase em Psicanálise, Saúde Mental e Saúde Pública.

País: Brasil Estado: Minas Gerais Cidade: Belo Horizonte

\section{RESUMO}

Objetivou-se analisar a produção científica brasileira acerca da relação entre o consumo de álcool e de outras drogas (AD) e a ocorrência da violência intrafamiliar (violência na família). Revisão integrativa, utilizando todas as bases de dados incluídas na Biblioteca Virtual em Saúde, selecionando artigos publicados entre 2013 a 2019, em português, disponíveis na íntegra eletronicamente e com acesso gratuito. A partir dos 42 estudos selecionados, foi possível observar um papel importante no consumo de álcool e de outras drogas na ocorrência da violência intrafamiliar, indicando, na maior parte dos artigos, o uso do AD como um dos principais fatores (propiciador, influenciador, motivador, desencadeador). Em contrapartida, também foi 
descrito que o consumo de AD pode ser consequência da violência intrafamiliar, podendo atuar como um ciclo de consumo e reação, atuando a violência como propulsora do uso e vice-versa, descrevendo o uso de AD como importante, mas não unicausal para a violência intrafamiliar. Foi possível analisar a interferência do consumo de AD na violência intrafamiliar, envolvendo os membros (mulheres, crianças, adolescentes, idosos) e sob vários aspectos, sugerindo que o álcool é a principal substância lícita envolvida no fenômeno da violência no Brasil, assim como outras drogas ilícitas, mesmo que em menor proporção. Apesar de a violência na família ser multifatorial, torna-se essencial considerar o efeito do consumo de AD na ocorrência desse agravo, pois eles ocorrem simultaneamente e compartilham um conjunto complexo de fatores de risco, com graves efeitos psicosocioeconômicos individuais e coletivos, requerendo ações intersetoriais para seu enfrentamento.

Palavras-chave: Violência na família. Bebidas alcoólicas. Comportamento de fumar. Abuso de drogas. Drogas ilícitas.

\section{ABSTRACT \\ OCCURRENCE OF DOMESTIC VIOLENCE RELATED TO THE CONSUMPTION OF ALCOHOL AND OTHER DRUGS IN BRAZIL}

The objective of this study was to analyze the brazilian scientific production about the relationship between alcohol consumption and other drugs (AD) and the occurrence of intrafamily violence (domestic violence). Integrative review, using all databases included in the Virtual Health Library, selecting articles published between 2013 and 2019, in portuguese, available in full electronically and with free access. From the 42 selected studies, it was possible to observe an important role in the consumption of alcohol and other drugs in the occurrence of intrafamily violence, indicating, in most articles, the use of AD as one of the main factors (propitiator, influencer, motivator, trigger). On the other hand, it has also been described that the consumption of $A D$ can be a consequence of intrafamily violence, and may act as a cycle of consumption and reaction, acting violence as a driving force for use as a consequence, describing the use of $A D$ as important, but not unique for intrafamily violence. It was possible to analyze the interference of $A D$ consumption in intrafamily violence, involving the various members (women, children, adolescents, the elderly) and in various aspects, suggesting that alcohol is the main licit substance involved in the phenomenon of violence in Brazil, as well as other illicit drugs, even in a lesser proportion. Although violence in the family is multifactorial, it's essential to consider the effect of $A D$ consumption in the occurrence of this aggravation, because they occur simultaneously and share a complex set of risk factors, with serious individual and collective psychosocioeconomic effects, requiring intersectoral actions for their coping.

Keywords: Domestic violence. Alcoholic beverages. Smoking behavior. Drug abuse.Street drugs.

Data de recebimento: 10/04/2019 - Data de aprovação: 13/08/2020

DOI: 10.31060/rbsp.2021.v15.n2.1212

\section{INTRODUÇÃO}

A violência na família (ou violência intrafamiliar) e o consumo de álcool e de outras drogas são dois grandes problemas de saúde pública em todo o mundo, segundo a Organização Mundial da Saúde - OMS (OMS, 2009). Além de suas altas prevalências, ambos os fenômenos resultam em consideráveis repercussões biológicas, psicológicas e sociais, sejam individuais ou coletivas. Com frequência, esses fenômenos 
ocorrem simultaneamente e compartilham um conjunto complexo de fatores de risco psicossociais (GEBARA et al., 2015).

Em relação à violência, a OMS (2002) a conceitua como:

O uso intencional da força física ou do poder, real ou em ameaça, contra si próprio, contra outra pessoa, ou contra um grupo ou uma comunidade, que resulte ou tenha grande possibilidade de resultar em lesão, morte, dano psicológico, deficiência de desenvolvimento ou privação. (OMS, 2002, p.5).

Destaca-se que o uso da palavra "poder" amplia a natureza dos atos violentos, saindo do conceito usual de apenas cunho físico, incluindo atos que resultem de uma relação de poder - ameaças, intimidações, privações, entre outros (OMS, 2002; SOUZA e SOUZA et al., 2015). A violência é um fenômeno complexo, com influências dos contextos histórico, social e político em que está inserida, envolvendo época, locais e circunstâncias do sujeito que a vivencia, não existindo um fator único que explique o porquê de as pessoas agirem violentamente (MINAYO et al., 2018). Assim, para ser enfrentada, é preciso a junção dos diversos seguimentos da sociedade saúde, educação, segurança pública, justiça criminal, entre outros (COSTA et al., 2015).

A violência pode ser classificada de diversas formas e conforme a intencionalidade do agente. Segundo as características daqueles que cometem o ato violento, é dividida entre: violência autodirigida (subdividida em comportamento suicida; pensamentos suicidas; tentativas de suicídio; agressão autoinfligida; automutilação); violência interpessoal (na família e entre parceiros íntimos; violência na comunidade - violência entre indivíduos sem relação pessoal); e violência coletiva (social, política e econômica, desencadeada por grandes grupos ou países). Quanto à natureza dos atos, pode ser: física; sexual; psicológica; relacionada à privação ou ao abandono (DAHLBERG; KRUG, 2006).

Neste estudo, o objeto central é a violência interpessoal, mais especificamente a violência na família ou intrafamiliar. A violência intrafamiliar é aquela praticada por um ou mais autores com laços familiares, conjugais ou de parentesco, ou com vínculo afetivo em condições de relação de poder, seja real ou de ameaça. Essa relação de poder pode ser física, etária, social, psíquica, hierárquica ou de gênero. Portanto, não se restringe apenas ao espaço físico onde a violência ocorre, mas, também, às relações em que os indivíduos constroem (BRASIL, 2002; BRASIL, 2008; MACHADO et al., 2014). É um fenômeno que afeta toda a sociedade, repercutindo em agressões contra as mulheres; por parceiro íntimo; contra crianças e adolescentes; contra idosos; e até contra portadores de deficiência física (DAHLBERG; KRUG, 2006). Devido aos seus impactos social, psicológico e econômico, a violência intrafamiliar é um importante problema de saúde pública no Brasil (MINAYO et al., 2018).

Para fins de compreensão da gênese da violência, a OMS estabeleceu um modelo ecológico em que explora a relação entre os fatores individuais e os externos na influência do comportamento (DAHLBERG; KRUG, 2006). No primeiro nível, busca-se compreender os fatores biológicos e da história pessoal que o sujeito traz para o seu comportamento, tais como impulsividade, uso de álcool e de outras drogas (AD), passado de agressão, abuso e omissão. No segundo nível, tenta-se compreender as relações sociais próximas que esse indivíduo estabelece (família e amigos), com grande influência na reação aos atos violentos (aumento do risco de vitimização ou agressão violenta). O contexto comunitário estabelecido nas relações sociais externas (escola, comunidade, bairros, locais de trabalho) define o terceiro nível e também se relaciona com o quarto e último nível, o qual compreende as normas sociais, culturais, legais e políticas que visam normatizar o convívio em sociedade (DAHLBERG; KRUG, 2006). 
Ao analisar esse modelo ecológico, é importante frisar, sem deixar de lado os demais fatores, o papel que o consumo e o abuso de substâncias químicas - destacando o álcool e outras drogas - assumem na ocorrência dos atos violentos.

As bebidas alcoólicas e as outras drogas estão descritas desde o início da humanidade, e o seu uso tem sido amplamente discutido ao longo dos anos (SILVEIRA; DOERING-SILVEIRA, 2017). As literaturas nacional e internacional têm apontado uma importante relação entre o uso de AD e a violência, encontrando este consumo em grande parte dos eventos violentos, principalmente no contexto intrafamiliar, agravado por condições particulares, individuais e familiares, tais como desequilíbrio emocional, famílias disfuncionais, crise ou perdas recentes, modelo familiar violento, entre outros (MARTINS; NASCIMENTO, 2017; LUCCHESE et al., 2017; AGUIAR; MENEZES, 2017; WARMLING; LINDNER; COELHO, 2017; ANDREUCCETTI et al., 2018; ARAÚJO et al., 2018). Embora alguns estudos relacionem o consumo de AD com o comportamento violento, não é possível estabelecer uma associação simples e unidirecional, devido à complexidade dessa relação (LARANJEIRA; DUAILIBI; PINSKY, 2005; BENNETT; O'BRIEN, 2007; GEBARA et al., 2015; ANDREUCCETTI et al., 2018).

A Lei n 11.343, de 2006, define como droga: "as substâncias ou produtos capazes de causar dependência", assim especificado no parágrafo único, art. $1^{\circ}$ (BRASIL, 2006a). No Brasil, atualmente, o álcool e o tabaco são considerados como drogas lícitas, acrescidos dos medicamentos psicotrópicos prescritos por médicos. Outras drogas conhecidas como a maconha, o crack, a cocaína, a dietilamida do ácido lisérgico (LSD), a metilenodioximetanfetamina (mais conhecida como ecstasy), os opiáceos, a heroína, entre outras, são descritas na lei como ilícitas, sendo vetados seu porte, consumo, fabricação e comercialização, acarretando comportamentos violentos em sua cadeia de produção, venda e consumo (BRASIL, 2006a).

O álcool tem o consumo admitido e, muitas vezes, incentivado pela sociedade, tornando-se um sério problema de saúde pública quando consumido de forma excessiva (GBD, 2018). Em contrapartida, as outras drogas são menos aceitas, sendo, na maioria das vezes, alvo de ações preconceituosas, o que aumenta o estigma de quem faz uso. Assim, é necessário compreender a dinâmica das relações que esses usuários estabelecem com o meio em que vivem, bem como diferenciar algumas práticas nem tão patológicas no consumo de AD, frisando que nem todo uso é problemático (BRASIL, 2003a).

É comum encontrar a utilização do termo "álcool e outras drogas" de forma associada, isso porque as substâncias psicoativas podem ser complementares, podendo o consumo de uma estar ligado ao consumo de outra. A OMS enfatiza que alcoolistas são mais propensos a serem fumantes de tabaco e consumidores frequentes de outras substâncias psicoativas; e que o consumo de duas ou mais substâncias em conjunto pode ter efeito multiplicativo - ao invés de aditivo (OMS, 2018a).

Especificamente sobre as bebidas alcoólicas, apesar de alguns estudos sugerirem que seu consumo esteve mais associado à gravidade dos atos de violência do que ao aumento de sua ocorrência (LEONARD, 2005; GRAHAM et al., 2011), outros sugerem que há relação de ambos - gravidade e aumento dos atos violentos (MOREIRA et al., 2008; TUMWESIGYE et al., 2012).

Segundo a Organização Mundial da Saúde, o consumo per capita de álcool puro no mundo é de 6,4 litros, com projeções de aumento para os próximos dez anos. Na região das Américas, o consumo per capita é de 8 litros e, no Brasil, o valor médio é de 7,8 litros. Quando se avaliaram somente as pessoas que fizeram uso nos 12 meses anteriores à pesquisa, $43 \%$ da população mundial estavam nessa categoria; $54,1 \%$ nas 
Américas; e 40\% no Brasil (OMS, 2018a). Mundialmente, há 1,1 bilhão de fumantes adultos no mundo e pelo menos 367 milhões de usuários de derivados do tabaco que "não produzem fumaça" (OMS, 2017).

A pesquisa Vigilância de Fatores de Risco e Proteção para Doenças Crônicas por Inquérito Telefônico (Vigitel) apontou que, em 2018, a frequência de adultos fumantes foi de 9,3\%. Já o consumo abusivo do álcool (consumo, em uma mesma ocasião, nos últimos 30 dias, de quatro ou mais doses para mulheres ou cinco ou mais doses para homem) foi de 17,9\% (BRASIL, 2019). Em 2017, o Instituto Nacional de Câncer José Alencar Gomes da Silva (Inca) fez uma estimativa da proporção de cigarros ilegais consumidos no Brasil, indicando 38,5\% do consumo desses cigarros (INCA, 2017).

Para entender melhor como o consumo de álcool e de outras drogas pode estar relacionado à maior gravidade da violência intrafamiliar, é importante considerar não apenas os efeitos farmacológicos dessas substâncias, mas, também, os fatores ambientais e socioculturais que influenciam os padrões de consumo e os comportamentos violentos (GRAHAM et al., 2011). Por serem importantes agravos no Brasil e no mundo, e por apresentarem relação entre eles, torna-se importante conhecer sobre o papel do consumo de AD na ocorrência da violência na família, principalmente no contexto brasileiro.

Assim, este estudo objetivou analisar a produção científica brasileira acerca da relação entre o consumo de álcool e de outras drogas e a ocorrência da violência intrafamiliar.

\section{METODOLOGIA}

\section{DEFINIÇÃO, PROTOCOLO E CRITÉRIOS DE ELEGIBILIDADE}

Trata-se de uma revisão integrativa da literatura, que visa reunir e sistematizar resultados de pesquisa sobre um determinado tema ou uma determinada questão, contribuindo para o aprofundamento do tema investigado. Neste estudo, iniciou-se com a definição do problema: Qual a relação entre o consumo de álcool e de outras drogas e a ocorrência da violência intrafamiliar no Brasil?

Esta revisão foi elaborada seguindo protocolos já estabelecidos e cientificamente aceitos (MENDES; SILVEIRA; GALVÃO, 2008; SOUZA; SILVA; CARVALHO, 2010). A elaboração da revisão integrativa foi sistematizada em obediência aos seguintes critérios definidos por Souza, Silva e Carvalho (2010): 1) estabelecimento do objetivo específico; 2) formulação dos questionamentos a serem respondidos ou da hipótese a ser testada; 3) levantamento para identificar e coletar o máximo de materiais relevantes de acordo com os critérios de inclusão e exclusão previamente estabelecidos. Os autores, então, avaliaram minuciosamente os critérios de métodos empregados no desenvolvimento dos estudos selecionados, a fim de determinarem se são validados metodologicamente. Esse processo resultou em uma redução de estudos incluídos na revisão. Os dados coletados foram interpretados e sistematizados, e as conclusões foram formuladas com base nos vários estudos selecionados.

A busca bibliográfica ocorreu na segunda quinzena de fevereiro de 2019, tendo sido realizada pelos autores, separadamente, para que houvesse validação da busca. Como critérios para seleção dos artigos, adotaram-se os seguintes: artigos (observacionais, experimentais, revisões, relatos de experiência, entre outros) que abordassem a temática da violência intrafamiliar, seja ela com envolvimento do autor ou da vítima e a relação com o consumo de AD; publicados no período de 2013 a 2019; em português; 
disponíveis na íntegra eletronicamente e com acesso gratuito. Reforça-se que foram excluídos os estudos que estavam repetidos nas bases de dados, as teses, dissertações e os relatórios técnicos. A definição do período se deu pela opção em analisar a literatura mais atual.

\section{FONTES DE INFORMAÇÃO E ESTRATÉGIAS DEBUSCA}

Para a coleta de dados, foram utilizadas todas as bases de dados incluídas na Biblioteca Virtual em Saúde (BVS). Foram utilizados descritores controlados, encontrados nos Descritores em Ciências da Saúde (DeCS): "Bebidas Alcoólicas", "Abuso de Álcool", "Alcoolismo", "Abuso de Drogas", "Dependência de Drogas", "Comportamento de Fumar", "Drogas Ilícitas", "Violência na Família", "Violência Doméstica", "Violência Infantil", "Violência Contra a Mulher", "Violência por Parceiro Íntimo", "Violência de Gênero", "Violência Contra o Idoso". Conceitualmente, a violência doméstica se distingue da intrafamiliar por incluir outros membros do grupo sem função parental, como agregados, empregados domésticos e visitantes periódicos (BRASIL, 2002). No entanto, o termo é comumente utilizado para designar a violência de gênero e contra crianças em situações de abuso e maus tratos, por isso, também foi utilizado como descritor nestarevisão.

Como descritor não controlado, utilizou-se o termo "Drogas Lícitas". Santos, Pimenta e Nobre (2007) explicam que os descritores controlados representam os termos registrados no DeCS e são utilizados para indexação de artigos nas bases de dados. Já os nãos controlados se referem a palavras ou sinônimos que a grafia e o significado representem o assunto a ser pesquisado, mas não são utilizados para a indexação dos artigos, não estando registradosnos DeCS. Contudo, quando estes são utilizados, proporcionam a busca/refinamento do material escolhido.Como operador booleano, foi utilizado o termo "AND" durante as buscas.Foram utilizadas 56 estratégias de busca, combinando os descritores (de dois em dois, por exemplo, "Bebidas Alcoólicas AND Violência na Família").

\section{SELEÇÃO E EXTRAÇÃO DOSDADOS}

A seleção das referências relevantes foi feita por todos os autores, considerando os títulos e os resumos, sendo que as discordâncias foram resolvidas por consenso. Se o resumo estava indisponível, era acessado o texto completo para determinara elegibilidade.A Figura 1 mostra o esquema representativo dos procedimentos de seleção dos artigos, indicando a amostra final de 42. 
Ocorrência de violência intrafamiliar relacionada ao consumo de álcool e outras drogas no Brasil

Grazielle Neves Soares, Marconi Moura Fernandes,

Aline Maria Figueiredo Ko da Cunha e Luís Paulo Souza e Souza

\section{FIGURA 1}

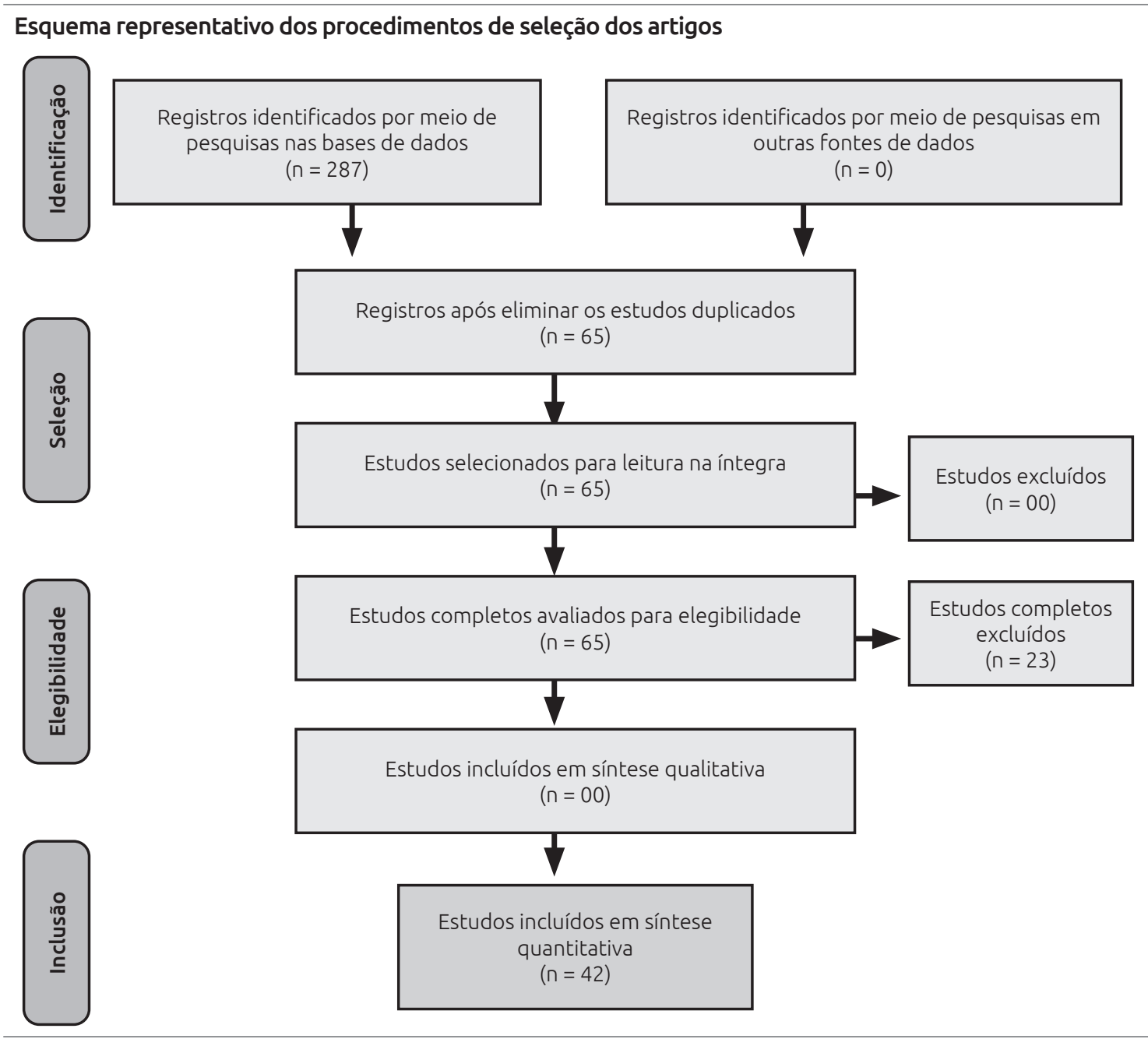

Fonte: Elaborado pelo autor (fev. 2019).

\section{ANÁLISE DOSDADOS}

Realizou-se a leitura na íntegra das 42 referências remanescentes, de forma interpretativa. Destaca-se que o processo de análise foi baseado em protocolos já estabelecidos (MENDES; SILVEIRA; GALVÃO, 2008; SAMPAIO), adaptados ao objeto deste estudo, e envolveu: caracterização de cada artigo selecionado (título, autores, ano de publicação, local de realização da pesquisa, população e tipo de estudo); avaliação da qualidade do conteúdo (conceitos importantes na área); tipos de drogas envolvidas entre os participantes dos estudos; comparação de possíveis fatores associados; discussão das ideias dos autores; conferição do método utilizado em cada referência; limitações dos estudos. 


\section{RESULTADOS}

Para facilitar a apresentação dos resultados, foram criados quadros sinópticos que contemplaram os aspectos considerados pertinentes. No Quadro 1, são apresentadas as características dos artigos segundo título; ano de publicação; revista; tipo/abordagem e local do estudo; população/público-alvo; e principais resultados. Observa-se que a maior parte dos estudos era do tipo transversal $(n=22 ; 52,4 \%)$, sendo onze descritivos e onze analíticos, publicados em 2017 ( $n=10 ; 23,8 \%$ ) e desenvolvidos na região Nordeste do Brasil ( $n=12 ; 28,6 \%)$.

Em relação à população ou ao público-alvo dos estudos, destaca-se maioria de mulheres ( $n=21 ; 50 \%$ ) (Figura 2), em circunstâncias diversas, tais como gestação, privação de liberdade, situação de rua, entre outras.

\section{FIGURA 2}

\section{Quantidade de artigos segundo população ou público-alvo envolvido na violência intrafamiliar nos estudos} incluídos nesta revisão

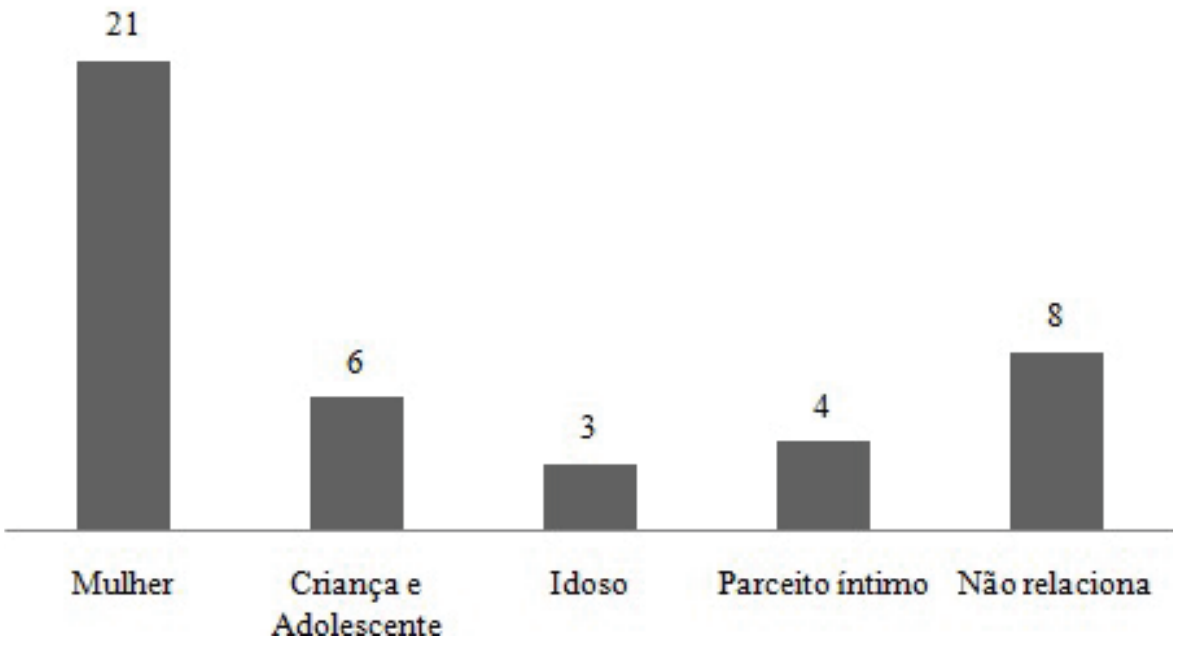

Fonte: Elaborado pelo autor (fev. 2019).

Quanto ao local em que os estudos foram desenvolvidos, destaca-se que a maior parte foi realizada em estabelecimentos de saúde ( $n=20 ; 47,61 \%)$, seguidos dos de segurança pública ( $n=9 ; 21,42 \%$ ), educacionais/escolares ( $n=2 ; 4,76 \%)$, domicílios [amostragem domiciliar] ( $n=3 ; 7,14 \%)$, e outros estabelecimentos $(n=8 ; 19,04 \%)$. 


\section{QUADRO 1}

\section{Descrição dos artigos incluídos na revisão segundo variáveis de interesse}

\begin{tabular}{|c|c|c|c|c|c|c|}
\hline $\begin{array}{l}\text { Ano de } \\
\text { publicação }\end{array}$ & Título & Revista & Tipo/abordagem & Local & \begin{tabular}{|l|} 
População/ \\
público-alvo
\end{tabular} & Principais resultados \\
\hline \multirow{9}{*}{2013} & $\begin{array}{l}\text { O alcoolismo na história } \\
\text { de vida de adolescentes: } \\
\text { uma análise à luz das } \\
\text { representações sociais }\end{array}$ & $\begin{array}{l}\text { Texto \& Contexto } \\
\text { Enfermagem }\end{array}$ & $\begin{array}{l}\text { Qualitativo } \\
\text { (história de vida e } \\
\text { observação livre) }\end{array}$ & $\begin{array}{l}\text { Belém do Pará } \\
\text {-Pará }\end{array}$ & $\begin{array}{l}\text { Adolescentes } \\
\text { participantes de } \\
\text { um projeto social }\end{array}$ & $\begin{array}{l}\text { Adolescentes que convivem com } \\
\text { alcoolistas têm mais risco de consumir } \\
\text { álcool e de seenvolver em violência; } \\
\text { Álcool aumenta a violência doméstica }\end{array}$ \\
\hline & $\begin{array}{l}\text { Fatores associados } \\
\text { à agressão física em } \\
\text { gestantes e os desfechos } \\
\text { negativos norecém- } \\
\text { nascido }\end{array}$ & $\begin{array}{l}\text { Jornal de } \\
\text { Pediatria }\end{array}$ & $\begin{array}{l}\text { Transversal } \\
\text { (analítico) }\end{array}$ & $\begin{array}{l}\text { Rio de Janeiro - } \\
\text { Rio de Janeiro }\end{array}$ & $\begin{array}{l}\text { Puérperas } \\
\text { hospitalizadas por } \\
\text { ocasião do parto }\end{array}$ & $\begin{array}{l}\text { Maior consumo de álcool e drogas } \\
\text { associam a violência pelo parceiro; } \\
\text { Quanto maior a violência pior o pré- } \\
\text { natal; } 36,2 \% \text { dasvítimas usaram álcool }\end{array}$ \\
\hline & \begin{tabular}{l|} 
Perfil da violência \\
doméstica e familiar \\
contra a mulher em \\
um município de Minas \\
Gerais, Brasil \\
\end{tabular} & $\begin{array}{l}\text { Cadernos Saúde } \\
\text { Coletiva }\end{array}$ & $\begin{array}{l}\text { Transversal } \\
\text { (descritivo) }\end{array}$ & $\begin{array}{l}\text { Alfenas-Minas } \\
\text { Gerais }\end{array}$ & $\begin{array}{l}\text { Mulheres } \\
\text { (Fonte: Boletins } \\
\text { de Ocorrência } \\
\text { Policial) }\end{array}$ & $\begin{array}{l}\text { Violência independe de raça, cor, } \\
\text { idade, etnia, religião ou condição social; } \\
\text { Poucainfluência de drogas; Maior } \\
\text { incidência: noite e fins desemana }\end{array}$ \\
\hline & $\begin{array}{l}\text { Mulheresemtratamento } \\
\text { ambulatorial por abuso } \\
\text { de álcool: características } \\
\text { sócio-demográficas e } \\
\text { clínicas }\end{array}$ & $\begin{array}{l}\text { Revista Gaúcha de } \\
\text { Enfermagem }\end{array}$ & $\begin{array}{l}\text { Transversal } \\
\text { (descritivo) }\end{array}$ & $\begin{array}{l}\text { Ribeirão Preto - } \\
\text { São Paulo }\end{array}$ & $\begin{array}{l}\text { Mulheres em } \\
\text { tratamento } \\
\text { ambulatorial por } \\
\text { abuso de álcool }\end{array}$ & $\begin{array}{l}\text { 40,7\% relataram violência familiar } \\
\text { e 9,5\% apontam a violência como } \\
\text { disparador do alcoolismo; } 81,5 \% \text { tinham } \\
\text { outro familiar alcoolista; } 92,6 \% \text { eram } \\
\text { mães }\end{array}$ \\
\hline & $\begin{array}{l}\text { Relação da violência } \\
\text { intrafamiliar e o uso } \\
\text { abusivo de álcool ou } \\
\text { entorpecentes na cidade } \\
\text { de Pelotas, RS }\end{array}$ & $\begin{array}{l}\text { Revista da } \\
\text { AMRIGS }\end{array}$ & $\begin{array}{l}\text { Transversal } \\
\text { (descritivo) }\end{array}$ & $\begin{array}{l}\text { Pelotas-Rio } \\
\text { Grande do Sul }\end{array}$ & \begin{tabular}{|l|} 
Membros da \\
família que \\
realizaram corpo \\
dedelito no \\
Instituo Médico \\
Legal (IML) \\
\end{tabular} & $\begin{array}{l}\text { 89\% eram do sexo feminino; Em } 86,6 \% \\
\text { o agressor era o companheiro; } 27,7 \% \\
\text { dosagressores ingeriram álcool; } 7,8 \% \\
\text { usou outras drogas; } 10,2 \% \text { ingeriu AD }\end{array}$ \\
\hline & $\begin{array}{l}\text { Perfil socioeconômico } \\
\text { e demográfico em uma } \\
\text { comunidade vulnerável } \\
\text { ao uso de drogas de } \\
\text { abuso }\end{array}$ & $\begin{array}{l}\text { Acta Paulista de } \\
\text { Enfermagem }\end{array}$ & $\begin{array}{l}\text { Transversal } \\
\text { (descritivo) }\end{array}$ & Não informado & \begin{tabular}{|l|} 
Moradores de uma \\
comunidade com \\
índices elevados \\
de violência \\
relacionados às \\
drogas \\
\end{tabular} & $\begin{array}{l}\text { Não relaciona violência e drogas; } 19,8 \% \\
\text { referiram problemas com drogas na } \\
\text { família; } 18,2 \% \text { referiram fazer uso de } \\
\text { alguma droga }\end{array}$ \\
\hline & $\begin{array}{l}\text { Exposição à violência } \\
\text { entre adolescentes de } \\
\text { uma comunidade de } \\
\text { baixa renda no Nordeste } \\
\text { do Brasil }\end{array}$ & $\begin{array}{l}\text { Ciência \& Saúde } \\
\text { Coletiva }\end{array}$ & $\begin{array}{l}\text { Transversal } \\
\text { (analítico) }\end{array}$ & Fortaleza-Ceará & \begin{tabular}{|l|} 
Adolescentes de \\
ambos os sexos, \\
residentes em \\
comunidade de \\
baixa renda \\
\end{tabular} & $\begin{array}{l}\text { 32,3\% referiram ter pais etilistas; } 26,2 \% \\
\text { consumiram álcool nos últimos seis } \\
\text { meses; } 23,8 \% \text { já fizeram uso de drogas; } \\
\text { 13,5\% fazem abuso do álcool; } 17,7 \% \\
\text { expostos àviolência }\end{array}$ \\
\hline & $\begin{array}{l}\text { Violência física por } \\
\text { parceiro íntimo na } \\
\text { gestação: prevalência } \\
\text { e alguns fatores } \\
\text { associados }\end{array}$ & Aquichan & $\begin{array}{l}\text { Transversal } \\
\text { (analítico) }\end{array}$ & Maringá-Paraná & $\begin{array}{l}\text { Рuérрeras } \\
\text { atendidas pelo } \\
\text { serviço de saúde }\end{array}$ & $\begin{array}{l}\text { 7,5\% tiveram algum episódio de } \\
\text { violência na gestação; Destas, } \\
5,9 \% \text { e } 13,3 \% \text { fizeram uso de } \\
\text { AD, respectivamente; } 17,9 \% \text { dos } \\
\text { companheiros estavam sob efeito de } \\
\text { drogas }\end{array}$ \\
\hline & $\begin{array}{l}\text { A importância da } \\
\text { família no processo de } \\
\text { prevenção da recaída no } \\
\text { alcoolismo }\end{array}$ & $\begin{array}{l}\text { Revista de } \\
\text { Enfermagem da } \\
\text { UERJ }\end{array}$ & $\begin{array}{l}\text { Qualitativo } \\
\text { (grupo focal) }\end{array}$ & $\begin{array}{l}\text { Rio de Janeiro- } \\
\text { Rio de Janeiro }\end{array}$ & $\begin{array}{l}\text { Usuários do } \\
\text { serviço da } \\
\text { Secretaria } \\
\text { Municipal de } \\
\text { Saúde/RJ } \\
\end{array}$ & $\begin{array}{l}\text { Maior demanda no grupo é motivada } \\
\text { pelaviolênciaintrafamiliarenãosomente } \\
\text { do alcoolismo, pois este leva à alteração } \\
\text { no comportamento }\end{array}$ \\
\hline \multirow{4}{*}{2014} & $\begin{array}{l}\text { Abuso de álcool e drogas } \\
\text { e violência contra as } \\
\text { mulheres: denúncias de } \\
\text { vividos }\end{array}$ & $\begin{array}{l}\text { Revista Вrasileira } \\
\text { de Enfermagem }\end{array}$ & $\begin{array}{l}\text { Qualitativo } \\
\text { (entrevistas semi } \\
\text { estruturadas) }\end{array}$ & $\begin{array}{l}\text { Rio Grande do } \\
\text { Sul-Rio Grande } \\
\text { do Sul }\end{array}$ & $\begin{array}{l}\text { Mulheres que } \\
\text { realizarama } \\
\text { denúncia da } \\
\text { violência do } \\
\text { companheiro } \\
\end{array}$ & $\begin{array}{l}\text { Uso de AD potencializou violência } \\
\text { nas mulheres entrevistadas; } 84,61 \% \\
\text { relacionou o uso de AD às agressões }\end{array}$ \\
\hline & $\begin{array}{l}\text { Violência conjugal: as } \\
\text { controvérsias no relato } \\
\text { dos parceiros íntimos em } \\
\text { inquéritos policiais }\end{array}$ & $\begin{array}{l}\text { Ciência \& Saúde } \\
\text { Coletiva }\end{array}$ & $\begin{array}{l}\text { Transversal } \\
\text { (quanti- } \\
\text { qualitativo, } \\
\text { descritivo) }\end{array}$ & $\begin{array}{l}\text { Florianópolis } \\
\text { - Santa Catarina }\end{array}$ & \begin{tabular}{l|} 
Casais (homens \\
e mulheres) com \\
caso de violência \\
descrito em \\
inquéritos policiais \\
\end{tabular} & $\begin{array}{l}\text { Principal motivo de agressão } \\
\text { para as mulheres é AD; Homens } \\
\text { responsabilizam as mulheres } \\
\text { pelaagressão e falam do álcool, mas não } \\
\text { de drogas }\end{array}$ \\
\hline & $\begin{array}{l}\text { Estudo sobre a violência } \\
\text { sexual em Serviço de } \\
\text { Atendimento à Mulher }\end{array}$ & $\begin{array}{l}\text { Revista de } \\
\text { Enfermagem da } \\
\text { UFPI }\end{array}$ & $\begin{array}{l}\text { Transversal } \\
\text { (descritivo) }\end{array}$ & Teresina-Piauí & $\begin{array}{l}\text { Mulheres } \\
\text { atendidas no } \\
\text { ambulatório }\end{array}$ & $\begin{array}{l}\text { Autores: } 46,82 \% \text { eram desconhecidos, } \\
\text { mas } 53,17 \% \text { haviam feito uso de } A D ; \\
\text { Vítimas: } 21,42 \% \text { haviam feito uso de AD, } \\
\text { mas } 61,12 \% \text { não haviam usado AD }\end{array}$ \\
\hline & $\begin{array}{l}\text { Prevalência e fatores } \\
\text { associados à violência } \\
\text { sofrida em mulheres } \\
\text { encarceradas por tráfico } \\
\text { de drogas no Estado de } \\
\text { Pernambuco, Brasil: um } \\
\text { estudo transversal }\end{array}$ & $\begin{array}{l}\text { Ciência \& Saúde } \\
\text { Coletiva }\end{array}$ & $\begin{array}{l}\text { Transversal } \\
\text { (analítico) }\end{array}$ & $\begin{array}{l}\text { Recife - } \\
\text { Pernambuco }\end{array}$ & $\begin{array}{l}\text { Mulheres privadas } \\
\text { de liberdades por } \\
\text { tráfico de drogas } \\
\text { em Colônia Penal } \\
\text { Feminina }\end{array}$ & $\begin{array}{l}\text { 78,9\% não brancas; } 85,8 \% \text { solteiras } \\
\text { com filhos; } 83,3 \% \text { tinham baixa } \\
\text { escolaridade; } 44,1 \% \text { são vítimas de } \\
\text { violênciaedestas } 44,1 \% \text { oagressorerao } \\
\text { companheiro; } 47,3 \% \text { fizeram uso de } \\
\text { drogas }\end{array}$ \\
\hline
\end{tabular}


Grazielle Neves Soares, Marconi Moura Fernandes, Aline Maria Figueiredo Ko da Cunha e Luís Paulo Souza e Souza

\begin{tabular}{|c|c|c|c|c|c|c|}
\hline \multirow{8}{*}{2015} & $\begin{array}{l}\text { Violência doméstica e } \\
\text { abuso de álcool e drogas } \\
\text { na adolescência }\end{array}$ & $\begin{array}{l}\text { Revista Ciência } \\
\text { Plural }\end{array}$ & $\begin{array}{l}\text { Transversal } \\
\text { (analítico) }\end{array}$ & $\begin{array}{l}\text { Natal-Rio } \\
\text { Grande do Norte }\end{array}$ & $\begin{array}{l}\text { Adolescentes } \\
\text { atendidos em } \\
\text { um Programa } \\
\text { de Assistência } \\
\text { à Saúde do } \\
\text { Adolescente }\end{array}$ & $\begin{array}{l}\text { Uso e abuso de AD são as principais } \\
\text { causas desencadeadoras de } \\
\text { situações de vulnerabilidade; } 30,5 \% \\
\text { identificamAD como um problema na } \\
\text { família }\end{array}$ \\
\hline & $\begin{array}{l}\text { A violência contra a } \\
\text { mulher em Montes } \\
\text { Claros }\end{array}$ & Barbarói & $\begin{array}{l}\text { Retrospectivo } \\
\text { (quanti- } \\
\text { qualitativo, } \\
\text { descritivo) }\end{array}$ & $\begin{array}{l}\text { Montes Claros - } \\
\text { Minas Gerais }\end{array}$ & $\begin{array}{l}\text { Mulheres que } \\
\text { registraram } \\
\text { boletim de } \\
\text { ocorrência de } \\
\text { violência } \\
\end{array}$ & $\begin{array}{l}53,9 \% \text { das vítimas já sofreram violência } \\
\text { antes; } 73,6 \% \text { dos agressores tinham } \\
\text { problema com álcool e } 18,1 \% \text { com } \\
\text { outras drogas }\end{array}$ \\
\hline & $\begin{array}{l}\text { Prevalência de violência } \\
\text { física por parceiro íntimo } \\
\text { em homens e mulheres } \\
\text { de Florianópolis, } \\
\text { SC, brasil: estudo de } \\
\text { basepopulacional }\end{array}$ & $\begin{array}{l}\text { Cadernos de } \\
\text { Saúde Pública }\end{array}$ & $\begin{array}{l}\text { Transversal } \\
\text { (analítico) }\end{array}$ & $\begin{array}{l}\text { Florianópolis } \\
\text { - Santa Catarina }\end{array}$ & $\begin{array}{l}\text { Adultos residentes } \\
\text { em zona urbana } \\
\text { do Município de } \\
\text { Florianópolis }\end{array}$ & $\begin{array}{l}\text { Mulheres são mais susceptíveis; } 18,5 \% \\
\text { fizeram uso abusivo de álcool; AD } \\
\text { apontado como um dos principais } \\
\text { motivos para a violência }\end{array}$ \\
\hline & $\begin{array}{l}\text { Notificações de violência } \\
\text { sexual contra a mulher } \\
\text { no Brasil }\end{array}$ & $\begin{array}{l}\text { Revista Brasileira } \\
\text { em Promoção da } \\
\text { Saúde }\end{array}$ & $\begin{array}{l}\text { Retrospectivo } \\
\text { (descritivo) }\end{array}$ & Brasil (SINAN) & $\begin{array}{l}\text { Notificações } \\
\text { relativas à } \\
\text { violência sexual } \\
\text { contra mulheres } \\
\text { de qualquer idade } \\
\end{array}$ & $\begin{array}{l}\text { 49,4\% das vítimas tinham de } 10 \text { a } 19 \\
\text { anos; } 60,6 \% \text { ocorreram na residência } \\
\text { da mulher; Em } 25,8 \% \text { o autor era } \\
\text { desconhecido; Em } 42,8 \% \text { não havia } \\
\text { suspeita de uso de álcool }\end{array}$ \\
\hline & $\begin{array}{l}\text { A dinâmica das relações } \\
\text { familiares de moradores } \\
\text { de rua usuários de crack }\end{array}$ & Saúde em Debate & $\begin{array}{l}\text { Qualitativo } \\
\text { (sócio-histórico) }\end{array}$ & $\begin{array}{l}\text { Florianópolis } \\
\text {-Santa Catarina }\end{array}$ & $\begin{array}{l}\text { Homens e } \\
\text { mulheres } \\
\text { moradores de rua } \\
\text { usuários de crack }\end{array}$ & $\begin{array}{l}\text { Família não é a única causa do crack, } \\
\text { mas destaca-se o exemplo do uso de AD } \\
\text { como disparador; A violência na família } \\
\text { foi a motivação para morar na rua e } \\
\text { consumir crack }\end{array}$ \\
\hline & $\begin{array}{l}\text { Uso de drogas, saúde } \\
\text { mental e problemas } \\
\text { relacionados ao crime } \\
\text { e à violência: estudo } \\
\text { transversal }\end{array}$ & $\begin{array}{l}\text { Revista Latino- } \\
\text { Americana de } \\
\text { Enfermagem }\end{array}$ & $\begin{array}{l}\text { Transversal } \\
\text { (descritivo) }\end{array}$ & $\begin{array}{l}\text { São Paulo-São } \\
\text { Paulo }\end{array}$ & $\begin{array}{l}\text { Adultos usuários } \\
\text { de álcool e/ou } \\
\text { de outras drogas } \\
\text { que buscaram } \\
\text { tratamento no } \\
\text { CAPSad } \\
\end{array}$ & $\begin{array}{l}85,2 \% \text { eram homens; Comum relação } \\
\text { entre transtornos psiquiátricos e uso } \\
\text { de substâncias; Quanto maiores os } \\
\text { sintomas internos maior a interação } \\
\text { com a violência }\end{array}$ \\
\hline & $\begin{array}{l}\text { Violência perpetrada } \\
\text { por parceiro íntimo à } \\
\text { gestante: o ambiente à } \\
\text { luz da teoria de Levine }\end{array}$ & $\begin{array}{l}\text { Revista da Escola } \\
\text { de Enfermagem } \\
\text { da USP }\end{array}$ & $\begin{array}{l}\text { Qualitativo } \\
\text { (entrevistas } \\
\text { semiestruturadas) }\end{array}$ & $\begin{array}{l}\text { Rio de Janeiro - } \\
\text { Rio de Janeiro }\end{array}$ & $\begin{array}{l}\text { Gestantes que } \\
\text { vivenciaram } \\
\text { a violência } \\
\text { perpetrada por } \\
\text { parceiro } \\
\end{array}$ & $\begin{array}{l}\text { 66,6\% sofreram violência física na } \\
\text { infância e na adolescência; Presenciaram } \\
\text { a mãe sendo agredida pelo pai } \\
\text { alcoolizado; Maior violência quando o } \\
\text { parceiro usa AD }\end{array}$ \\
\hline & $\begin{array}{l}\text { Violência contra a } \\
\text { mulher: agressores } \\
\text { usuários de drogas } \\
\text { ilícitas }\end{array}$ & $\begin{array}{l}\text { Revista de } \\
\text { Pesquisa Cuidado } \\
\text { é Fundamental }\end{array}$ & $\begin{array}{l}\text { Retrospectivo } \\
\text { (descritivo, } \\
\text { documental) }\end{array}$ & $\begin{array}{l}\text { Rio Grande-Rio } \\
\text { Grande do Sul }\end{array}$ & $\begin{array}{l}\text { Inquéritos policiais } \\
\text { de violência } \\
\text { contra Mulheres } \\
\text { em Delegacia de } \\
\text { Polícia }\end{array}$ & $\begin{array}{l}\text { 62,8\% eram parceiros íntimos; } 100 \% \\
\text { estavam sob o efeito de drogas; } 50,8 \% \\
\text { também estavam alcoolizados; } 72,8 \% \\
\text { tinham antecedentes criminais }\end{array}$ \\
\hline
\end{tabular}


Ocorrência de violência intrafamiliar relacionada ao

consumo de álcool e outras drogas no Brasil

Grazielle Neves Soares, Marconi Moura Fernandes,

Aline Maria Figueiredo Ko da Cunha e Luís Paulo Souza e Souza

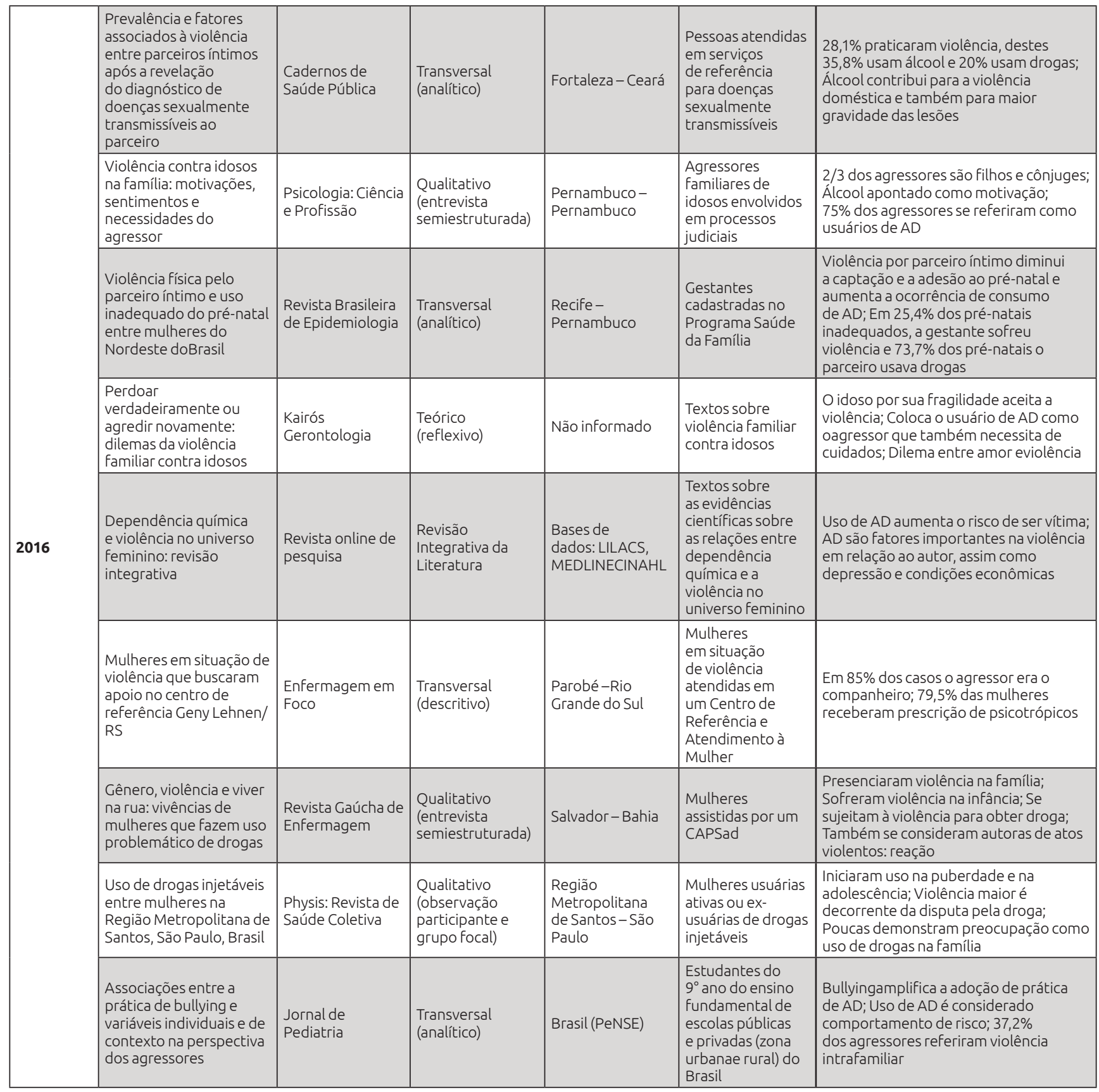

continua 
Grazielle Neves Soares, Marconi Moura Fernandes, Aline Maria Figueiredo Ko da Cunha e Luís Paulo Souza e Souza

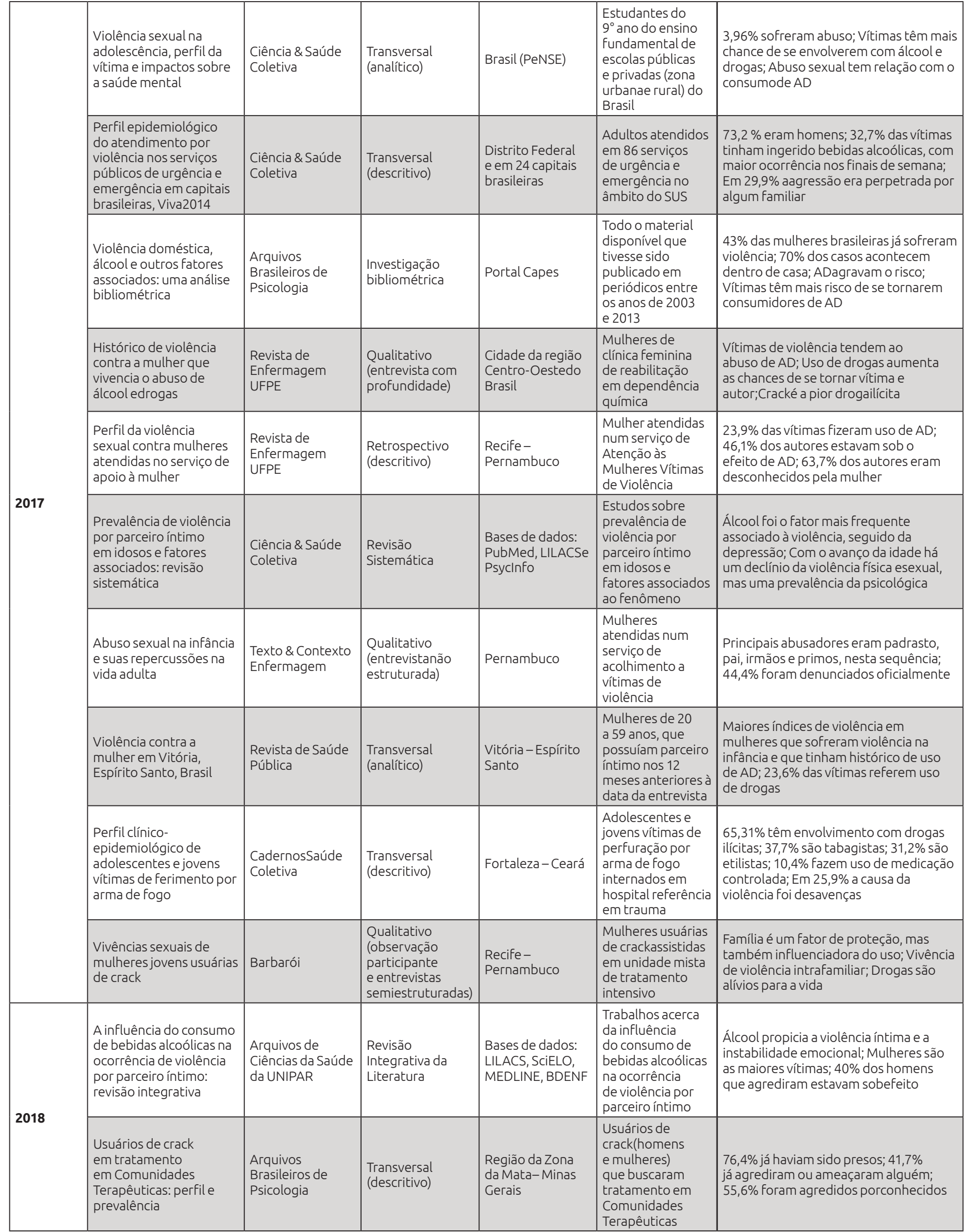

Notas: PubMed: Base bibliográfica da National Library of Medicine; LILACS: Literatura Latino-Americana e do Caribe em Ciências da Saúde; Psyclnfo: Base bibliográfica da American PsychologicalAssociation; SciELO: Scientific Eletronic Library Online; MEDLINE: Medical Literature Analysis and Retrieval System Online; BDENF: Banco de Dados em Enfermagem; CINAHL: Cummulative Index toNursing and Allied Health Literature; CAPSad: Centro de Atenção Psicossocial Álcool e Drogas; SINAN: Sistema de Informação de Agravos de Notificação; PeNSE: Pesquisa Nacional de Saúde do Escolar; Portal Capes: Coordenação de Aperfeiçoamento de Pessoal de Nível Superior. 
O Quadro 2 traz a descrição dos artigos brasileiros incluídos na revisão segundo variáveis de interesse relacionadas às formas de uso da droga, aos tipos de violência analisados e à relação entre AD, violência intrafamiliar e violência em geral. Assim, foi possível observar que a maior parte dos estudos não traz uma padronização do consumo da droga, citando apenas o uso ( $n=23 ; 54,76 \%$ ), sem especificar sua classificação (uso, abuso ou dependência). Nove artigos $(21,42 \%)$ descreveram outros padrões, porém, também relacionados ao uso, tais como as palavras "uso", "ingesta", "consumo", "uso regular", "uso abusivo", "sob efeito" e "uso problemático". Poucos autores utilizaram o termo "dependência" ( $n=10 ; 23,8 \%$ ).

Em relação à droga analisada, com maior frequência, foi relacionado o termo "álcool e outras drogas" ( $n=20 ; 47,61 \%)$, não descrevendo quaistipos seriam (lícitas ou ilícitas). Alguns autores descreveram outras drogas como tabaco $(n=7 ; 16,66 \%)$, crack $(n=6 ; 14,28 \%)$ e maconha $(n=3 ; 7,14 \%)$. O álcool foi relacionado em 36 artigos $(85,71 \%)$ e, isoladamente, em $6(14,28 \%)$. Três estudos $(7,14 \%)$ citaram apenas o termo "drogas" e um artigo $(0,42 \%)$ descreveu a prescrição de psicotrópicos pormédicos.Sobre os tipos de violências, em 11 artigos (26,19\%) não houve distinção do tipo de violência, sendo tratada em termos gerais. A maioria descreveu ocorrência de violência física $(n=23 ; 54,72 \%)$, seguida das violências sexual ( $n=19 ; 45,23 \%)$ e psicológica ( $n=18 ; 42,85 \%)$. Citaram-se, também, violência patrimonial $(n=6 ; 14,28 \%)$, moral $(n=5 ; 11,9 \%)$, negligência $(n=4 ; 9,52 \%)$, de gênero $(n=2 ; 4,76 \%)$ e abandono $(n=1 ; 2,38 \%)$.

De acordo com a intenção do agente, alguns artigos ( $n=22 ; 52,38 \%$ ) descreveram a violência de forma geral na comunidade e, também, na família. Outros estudos trataram de descrever apenas a violência intrafamiliar ( $n=13 ; 30,95 \%)$ ou apenas a violência em geral $(n=7 ; 16,66 \%)$, mas foram mantidos na amostra final desta revisão por demonstrarem relação com o consumo de AD e o impacto nas famílias.Na maioria dos artigos ( $n=18 ; 42,85 \%$ ), os autores indicaram o uso de $A D$ como um dos principais fatores (propiciador, influenciador, motivador ou desencadeador) da violência intrafamiliar. Em contrapartida, também foi descrito que o consumo de AD pode ser consequência da violência intrafamiliar, podendo atuar como um ciclo de consumo e reação, sendo a violência uma propulsora do uso e vice-versa, descrevendo o uso/consumo de álcool e de outras drogas como importante, mas não unicausal para a violênciaintrafamiliar.

\section{DISCUSSÃO}

Para facilitar a compreensão do contexto da violência intrafamiliar, foram estabelecidas quatro categorias a partir do público-alvo dos estudos, que serão debatidas a seguir, levando em consideração o consumo de álcool e de outras drogas e a violência: a) contra o idoso; b) contra crianças e adolescentes; c) por parceiro intimo e contra as mulheres; d) contra os demais membros da família.

Antes de seguir com a discussão dos grupos familiares, torna-se importante destacar a limitação na padronização nos artigos aqui incluídos em relação à utilização dos termos "uso", "abuso", "consumo", "dependência" e "ingestão". Os padrões de consumo podem ser basicamente conceituados como uso, abuso e dependência, sendo o termo "uso" mais amplamente utilizado para delimitar o consumo de substância psicoativa, seja esporádico, episódico ou contínuo. O abuso ou uso nocivo está associado a algum nível de prejuízo físico ou mental no indivíduo, enquanto que, na dependência, ocorre a dificuldade no controle do consumo da substância, que leva a pessoa a agir de forma repetida e impulsiva, causando grande impacto na vida. Ressalta-se que a dependência de drogas não pode ser definida apenas em função da quantidade e frequência de uso, mas sim no contexto em que se dá o uso, variando de 
pessoa para pessoa. Fato é que nem todo usuário de AD vai se tornar dependente, pois este fenômeno é extremamente complexo e envolve uma série de fatores internos e externos - biológicos, da própria substância e o contexto social que o sujeito está inserido (SILVEIRA; DOERING-SILVEIRA,2017).

\section{QUADRO 2}

\section{Descrição dos artigos brasileiros incluídos na revisão segundo variáveis de interesse relacionadas às formas de uso da droga, aos tipos de violência analisados e à relação entre álcool e drogas e a violência intrafamiliar}

\begin{tabular}{|c|c|c|c|c|c|c|}
\hline Título & Droga analisada & $\begin{array}{l}\text { Padrão de } \\
\text { consumo }\end{array}$ & $\begin{array}{l}\text { Tipos de violências } \\
\text { descritos }\end{array}$ & $\begin{array}{l}\text { Relação } \\
\text { entre AD } \\
\text { e violência } \\
\text { em geral }\end{array}$ & $\begin{array}{l}\text { Relação AD } \\
\text { e a violência } \\
\text { intrafamiliar }\end{array}$ & $\begin{array}{l}\text { Relação "Causa e } \\
\text { Efeito"** entre AD } \\
\text { e violência }\end{array}$ \\
\hline $\begin{array}{l}\text { O alcoolismo na história de vida } \\
\text { de adolescentes: uma análise à } \\
\text { luz das representações sociais }\end{array}$ & Álcool & Uso & $\begin{array}{l}\text { Não descreve os tipos } \\
\text { de agressão }\end{array}$ & $\operatorname{Sim}$ & $\operatorname{Sim}$ & Causa e Efeito \\
\hline $\begin{array}{l}\text { Fatores associados à agressão } \\
\text { física em gestantes e os } \\
\text { desfechos negativos norecém- } \\
\text { nascido }\end{array}$ & $\begin{array}{l}\text { Álcool e outras } \\
\text { drogas* }\end{array}$ & Uso & $\begin{array}{l}\text { Violência física } \\
\text { (agressão) }\end{array}$ & $\operatorname{Sim}$ & Sim & Causa e Efeito \\
\hline $\begin{array}{l}\text { Perfil da violência doméstica e } \\
\text { familiar contra a mulher em um } \\
\text { município de Minas Gerais, Brasil }\end{array}$ & $\begin{array}{l}\text { Álcool e substâncias } \\
\text { tóxicas * }\end{array}$ & Estar sob o efeito & $\begin{array}{l}\text { Violência física e } \\
\text { psicológica }\end{array}$ & $\operatorname{sim}$ & Sim & AD propicia Violência \\
\hline $\begin{array}{l}\text { Mulheres em tratamento } \\
\text { ambulatorial por abuso de } \\
\text { álcool: características sócio- } \\
\text { demográficas e clínicas }\end{array}$ & Álcool & $\begin{array}{l}\text { Dependência do } \\
\text { álcool }\end{array}$ & $\begin{array}{l}\text { Não descreve os tipos } \\
\text { de agressão. }\end{array}$ & $\operatorname{Sim}$ & Sim & $\begin{array}{l}\text { Violência leva ao } \\
\text { consumo de álcool }\end{array}$ \\
\hline $\begin{array}{l}\text { Relação da violência intrafamiliar } \\
\text { e o uso abusivo de álcool ou } \\
\text { entorpecentes na cidade de } \\
\text { Pelotas, RS }\end{array}$ & $\begin{array}{l}\text { Álcool e outras } \\
\text { drogas* }\end{array}$ & Uso & $\begin{array}{l}\text { Violência física (lesão } \\
\text { corрoral) }\end{array}$ & $\operatorname{Sim}$ & Sim & AD propicia Violência \\
\hline $\begin{array}{l}\text { Perfil socioeconômico } \\
\text { e demográfico em uma } \\
\text { comunidade vulnerável ao uso } \\
\text { de drogas de abuso }\end{array}$ & $\begin{array}{l}\text { Álcool, tabaco e } \\
\text { outras drogas* }\end{array}$ & Uso & $\begin{array}{l}\text { Não descreve os tipos } \\
\text { de violência }\end{array}$ & $\operatorname{Sim}$ & Não & Não relaciona \\
\hline $\begin{array}{l}\text { Exposição à violência entre } \\
\text { adolescentes de uma } \\
\text { comunidade de baixa renda no } \\
\text { Nordeste do Brasil }\end{array}$ & $\begin{array}{l}\text { Álcool e outras } \\
\text { drogas* }\end{array}$ & Uso & $\begin{array}{l}\text { Não descreve os tipos } \\
\text { de violência }\end{array}$ & $\operatorname{Sim}$ & Não & Não relaciona \\
\hline $\begin{array}{l}\text { Violência física por parceiro } \\
\text { íntimo na gestação: prevalência e } \\
\text { alguns fatores associados }\end{array}$ & $\begin{array}{l}\text { Álcool, tabaco e } \\
\text { outras drogas* }\end{array}$ & Uso & Violência física & Não & $\operatorname{sim}$ & AD propicia Violência \\
\hline $\begin{array}{l}\text { A importância da família no } \\
\text { processo de prevenção da } \\
\text { recaída no alcoolismo }\end{array}$ & Álcool & Dependência & $\begin{array}{l}\text { Não descreve os tipos } \\
\text { de agressão }\end{array}$ & Sim & Sim & Causa e Efeito \\
\hline $\begin{array}{l}\text { Abuso de álcool e drogas e } \\
\text { violência contra as mulheres: } \\
\text { denúncias de vividos }\end{array}$ & $\begin{array}{l}\text { Álcool, cracke } \\
\text { outras drogas* }\end{array}$ & Uso & $\begin{array}{l}\text { Não descreve os tipos } \\
\text { de violência }\end{array}$ & Não & Sim & AD propicia Violência \\
\hline $\begin{array}{l}\text { Violência conjugal: as } \\
\text { controvérsias no relato dos } \\
\text { parceiros íntimos em inquéritos } \\
\text { policiais }\end{array}$ & $\begin{array}{l}\text { Álcool e outras } \\
\text { drogas* }\end{array}$ & Uso & $\begin{array}{l}\text { Não descreve os tipos } \\
\text { de violência }\end{array}$ & Não & Sim & AD propicia Violência \\
\hline $\begin{array}{l}\text { Estudo sobre a violência sexual } \\
\text { em Serviço de Atendimento à } \\
\text { Mulher }\end{array}$ & $\begin{array}{l}\text { Álcool e outras } \\
\text { drogas* }\end{array}$ & Uso & Violência sexual & $\operatorname{Sim}$ & $\operatorname{sim}$ & AD propicia Violência \\
\hline $\begin{array}{l}\text { Prevalência e fatores associados } \\
\text { à violência sofrida em } \\
\text { mulheres encarceradas por } \\
\text { tráfico de drogas no Estado } \\
\text { de Pernambuco, Brasil: um } \\
\text { estudotransversal }\end{array}$ & Drogas* & Uso & $\begin{array}{l}\text { Não descreve os tipos } \\
\text { de violência }\end{array}$ & $\operatorname{Sim}$ & Sim & Não relaciona \\
\hline $\begin{array}{l}\text { Violência doméstica e abuso de } \\
\text { álcool e drogas na adolescência }\end{array}$ & \begin{tabular}{|l|} 
Álcool e outras \\
drogas*
\end{tabular} & Uso e abuso & $\begin{array}{l}\text { Não descreve os tipos } \\
\text { de violência }\end{array}$ & $\operatorname{Sim}$ & Não & Causa e Efeito \\
\hline $\begin{array}{l}\text { A violência contra a mulher em } \\
\text { Montes Claros }\end{array}$ & $\begin{array}{l}\text { Álcool e outras } \\
\text { drogas* }\end{array}$ & $\begin{array}{l}\text { Problemas com o } \\
\text { álcool e drogas }\end{array}$ & \begin{tabular}{|l} 
Violência física, \\
psicológica e sexual
\end{tabular} & $\operatorname{Sim}$ & Sim & AD propicia Violência \\
\hline
\end{tabular}


Grazielle Neves Soares, Marconi Moura Fernandes,

Aline Maria Figueiredo Ko da Cunha e Luís Paulo Souza e Souza

\begin{tabular}{|c|c|c|c|c|c|c|}
\hline Título & Droga analisada & $\begin{array}{l}\text { Padrão de } \\
\text { consumo }\end{array}$ & $\begin{array}{l}\text { Tipos de violências } \\
\text { descritos }\end{array}$ & \begin{tabular}{|l|} 
Relação \\
entre AD \\
e violência \\
em geral \\
\end{tabular} & $\begin{array}{l}\text { Relação AD } \\
\text { e a violência } \\
\text { intrafamiliar }\end{array}$ & $\begin{array}{l}\text { Relação "Causa e } \\
\text { Efeito"** entre AD } \\
\text { e violência }\end{array}$ \\
\hline $\begin{array}{l}\text { Prevalência de violência física } \\
\text { por parceiro íntimo em homens } \\
\text { e mulheres de Florianópolis, } \\
\text { SC, Brasil: estudo de base } \\
\text { populacional }\end{array}$ & Álcool & Abuso & Violência física & Não & Sim & Causa e Efeito \\
\hline $\begin{array}{l}\text { Notificações de violência sexual } \\
\text { contra a mulher no Brasil }\end{array}$ & Álcool & Uso & Violência sexual & $\operatorname{Sim}$ & Não & AD propicia Violência \\
\hline $\begin{array}{l}\text { A dinâmica das relações } \\
\text { familiares de moradores de rua } \\
\text { usuários de crack }\end{array}$ & Crack & Uso & $\begin{array}{l}\text { Não descreve os tipos } \\
\text { de violência }\end{array}$ & $\operatorname{Sim}$ & Sim & $\begin{array}{l}\text { Violência leva ao } \\
\text { consumo de AD }\end{array}$ \\
\hline $\begin{array}{l}\text { Uso de drogas, saúde mental e } \\
\text { problemas relacionados ao crime } \\
\text { e à violência: estudo transversal }\end{array}$ & $\begin{array}{l}\text { Álcool e outras } \\
\text { drogas* }\end{array}$ & Uso & $\begin{array}{l}\text { Não descreve os tipos } \\
\text { de violência }\end{array}$ & $\operatorname{Sim}$ & Não & AD propicia Violência \\
\hline $\begin{array}{l}\text { Violência perpetrada por } \\
\text { parceiro íntimo à gestante: } \\
\text { o ambiente à luz da teoria } \\
\text { deLevine }\end{array}$ & $\begin{array}{l}\text { Álcool e outras } \\
\text { drogas* }\end{array}$ & Uso & $\begin{array}{l}\text { Violência física, } \\
\text { patrimonial, moral, } \\
\text { sexual e psicológica }\end{array}$ & Não & $\operatorname{Sim}$ & AD propicia Violência \\
\hline $\begin{array}{l}\text { Violência contra a mulher: } \\
\text { agressores usuários de drogas } \\
\text { ilícitas }\end{array}$ & $\begin{array}{l}\text { Álcool e outras } \\
\text { drogas* }\end{array}$ & Estar sob efeito & $\begin{array}{l}\text { Violência física, } \\
\text { patrimonial, moral, } \\
\text { sexual e psicológica }\end{array}$ & $\operatorname{Sim}$ & Sim & AD propicia Violência \\
\hline $\begin{array}{l}\text { Prevalência e fatores associados } \\
\text { à violência entre parceiros } \\
\text { íntimos após a revelação do } \\
\text { diagnóstico de } \\
\text { doenças sexualmente } \\
\text { transmissíveis ao parceiro }\end{array}$ & $\begin{array}{l}\text { Álcool e outras } \\
\text { drogas* }\end{array}$ & Uso & $\begin{array}{l}\text { Violência física, sexual e } \\
\text { psicológica }\end{array}$ & Não & Sim & AD propicia Violência \\
\hline $\begin{array}{l}\text { Violência contra idosos na } \\
\text { família: motivações, sentimentos } \\
\text { e necessidades do agressor }\end{array}$ & $\begin{array}{l}\text { Álcool e outras } \\
\text { drogas* }\end{array}$ & Uso & $\begin{array}{l}\text { Violência física e } \\
\text { psicológica (agressão } \\
\text { verbal e física) }\end{array}$ & Não & Sim & AD propicia Violência \\
\hline $\begin{array}{l}\text { Notificações de violência sexual } \\
\text { contra a mulher no Brasil }\end{array}$ & Álcool & Uso & Violência sexual & $\operatorname{Sim}$ & Não & AD propicia Violência \\
\hline $\begin{array}{l}\text { Violência física pelo parceiro } \\
\text { íntimo e uso inadequado do } \\
\text { pré-natal entre mulheres do } \\
\text { Nordeste do Brasil }\end{array}$ & $\begin{array}{l}\text { Álcool, tabaco e } \\
\text { drogas* ilícitas }\end{array}$ & $\begin{array}{l}\text { Uso e } \\
\text { dependência } \\
\text { (tabagismo) }\end{array}$ & Violência física & Não & Sim & Causa e Efeito \\
\hline $\begin{array}{l}\text { Perdoar verdadeiramente ou } \\
\text { agredir novamente: dilemas da } \\
\text { violência familiar contra idosos }\end{array}$ & Drogas* & Uso & $\begin{array}{l}\text { Violência física e } \\
\text { psicológica(verbal, } \\
\text { gestual epostural) }\end{array}$ & $\operatorname{Sim}$ & $\operatorname{Sim}$ & AD propicia Violência \\
\hline $\begin{array}{l}\text { Dependência química e violência } \\
\text { no universo feminino: revisão } \\
\text { integrativa }\end{array}$ & $\begin{array}{l}\text { Álcool e outras } \\
\text { drogas* }\end{array}$ & $\begin{array}{l}\text { Uso e } \\
\text { dependência }\end{array}$ & $\begin{array}{l}\text { Violência física e } \\
\text { psicológica }\end{array}$ & Não & Sim & AD propicia Violência \\
\hline $\begin{array}{l}\text { Mulheres em situação de } \\
\text { violência que buscaram apoio } \\
\text { no centro de referência } \\
\text { GenyLehnen/RS }\end{array}$ & Psicotrópicos & Uso prescrito & $\begin{array}{l}\text { Violência física, } \\
\text { psicológica,sexual, } \\
\text { patrimonial emoral }\end{array}$ & $\operatorname{Sim}$ & Sim & $\begin{array}{l}\text { Violência leva } \\
\text { àprescrição de } \\
\text { psicotrópicos }\end{array}$ \\
\hline $\begin{array}{l}\text { Gênero, violência e viver na rua: } \\
\text { vivências de mulheres que fazem } \\
\text { uso problemático de drogas }\end{array}$ & $\begin{array}{l}\text { Álcool e outras } \\
\text { drogas* }\end{array}$ & $\begin{array}{l}\text { Uso, abuso e } \\
\text { dependência }\end{array}$ & $\begin{array}{l}\text { Violência física, sexual, } \\
\text { moral e de gênero }\end{array}$ & Sim & Sim & Causa e Efeito \\
\hline $\begin{array}{l}\text { Uso de drogas injetáveis } \\
\text { entre mulheres na Região } \\
\text { Metropolitana de Santos, São } \\
\text { Paulo, Brasil }\end{array}$ & $\begin{array}{l}\text { Cocaína, crack, } \\
\text { álcool e maconha }\end{array}$ & $\begin{array}{l}\text { Uso e } \\
\text { dependência }\end{array}$ & $\begin{array}{l}\text { Violência física, } \\
\text { psicológica, sexual, de } \\
\text { gênero e negligência }\end{array}$ & Sim & Sim & Causa e Efeito \\
\hline $\begin{array}{l}\text { Associaç̃oes entre a prática de } \\
\text { bullying e variáveis individuais e } \\
\text { de contexto na perspectiva dos } \\
\text { agressores }\end{array}$ & $\begin{array}{l}\text { Álcool, tabaco e } \\
\text { outras drogas* }\end{array}$ & Uso regular & Violência psicológica & $\operatorname{sim}$ & Sim & Causa e Efeito \\
\hline $\begin{array}{l}\text { Violência sexual na adolescência, } \\
\text { perfil da vítima e impactos sobre } \\
\text { a saúde mental }\end{array}$ & $\begin{array}{l}\text { Álcool e outras } \\
\text { drogas* }\end{array}$ & Uso & Violência sexual & Sim & Sim & Causa e Efeito \\
\hline $\begin{array}{l}\text { Perfil epidemiológico do } \\
\text { atendimento por violência nos } \\
\text { serviços públicos de urgência } \\
\text { e emergência em capitais } \\
\text { brasileiras, Viva } 2014\end{array}$ & $\begin{array}{l}\text { Álcool e outras } \\
\text { drogas* }\end{array}$ & Uso & Violência física & Sim & Sim & Causa e Efeito \\
\hline $\begin{array}{l}\text { Violência doméstica, álcool e } \\
\text { outros fatores associados: uma } \\
\text { análise bibliométrica }\end{array}$ & $\begin{array}{l}\text { Álcool e outras } \\
\text { drogas* }\end{array}$ & Uso & $\begin{array}{l}\text { Violência física, } \\
\text { sexual,moral, } \\
\text { patrimonial,psicológica } \\
\text { enegligência }\end{array}$ & Não & Sim & Causa e Efeito \\
\hline
\end{tabular}




\begin{tabular}{|c|c|c|c|c|c|c|}
\hline Título & Droga analisada & $\begin{array}{l}\text { Padrão de } \\
\text { consumo }\end{array}$ & $\begin{array}{l}\text { Tipos de violências } \\
\text { descritos }\end{array}$ & \begin{tabular}{|l|} 
Relação \\
entre AD \\
e violência \\
em geral \\
\end{tabular} & $\begin{array}{l}\text { Relação AD } \\
\text { e a violência } \\
\text { intrafamiliar }\end{array}$ & $\begin{array}{l}\text { Relação "Causa e } \\
\text { Efeito"** entre AD } \\
\text { e violência }\end{array}$ \\
\hline $\begin{array}{l}\text { Histórico de violência contra a } \\
\text { mulher que vivencia o abuso de } \\
\text { álcool e drogas }\end{array}$ & $\begin{array}{l}\text { Álcool, crack, } \\
\text { cocaína e maconha }\end{array}$ & $\begin{array}{l}\text { Abuso e } \\
\text { dependência }\end{array}$ & $\begin{array}{l}\text { Violência física, sexual e } \\
\text { psicológica }\end{array}$ & Sim & Sim & Causa e Efeito \\
\hline $\begin{array}{l}\text { Perfil da violência sexual contra } \\
\text { mulheres atendidas no serviço } \\
\text { de apoio à mulher }\end{array}$ & $\begin{array}{l}\text { Álcool e outras } \\
\text { drogas* }\end{array}$ & $\begin{array}{l}\text { Uso e estar sob } \\
\text { efeito }\end{array}$ & $\begin{array}{l}\text { Violência sexual e } \\
\text { psicológica }\end{array}$ & $\operatorname{Sim}$ & Sim & Causa e Efeito \\
\hline $\begin{array}{l}\text { Prevalência de violência por } \\
\text { parceiro íntimo em idosos e } \\
\text { fatores associados: revisão } \\
\text { sistemática }\end{array}$ & $\begin{array}{l}\text { Álcool, tabaco e } \\
\text { outras drogas* }\end{array}$ & Uso & $\begin{array}{l}\text { Violência psicológica, } \\
\text { física, sexual, } \\
\text { econômica, negligência }\end{array}$ & Não & Sim & AD propicia Violência \\
\hline $\begin{array}{l}\text { Abuso sexual na infância e suas } \\
\text { repercussões na vida adulta }\end{array}$ & $\begin{array}{l}\text { Álcool e outras } \\
\text { drogas* }\end{array}$ & Uso & Violência sexual & Sim & Sim & Causa e Efeito \\
\hline $\begin{array}{l}\text { Violência contra a mulher em } \\
\text { Vitória, Espírito Santo, Brasil }\end{array}$ & $\begin{array}{l}\text { Álcool, tabaco e } \\
\text { outras drogas* }\end{array}$ & $\begin{array}{l}\text { Uso e ingestão } \\
\text { (descreve a } \\
\text { quantidade do } \\
\text { álcool) }\end{array}$ & $\begin{array}{l}\text { Violência psicológica, } \\
\text { física e sexual }\end{array}$ & Não & Sim & Causa e Efeito \\
\hline $\begin{array}{l}\text { Perfil clínico-epidemiológico de } \\
\text { adolescentes e jovens vítimas de } \\
\text { ferimento por arma de fogo }\end{array}$ & $\begin{array}{l}\text { Álcool, crack, } \\
\text { cocaína, maconha, } \\
\text { tabaco e outras } \\
\text { drogas }\end{array}$ & $\begin{array}{l}\text { Uso e } \\
\text { dependência }\end{array}$ & Violência física & Sim & Não & AD propicia Violência \\
\hline $\begin{array}{l}\text { Vivências sexuais de mulheres } \\
\text { jovens usuárias de crack }\end{array}$ & Crack & Dependência & $\begin{array}{l}\text { Violência sexual, } \\
\text { negligência e abandono }\end{array}$ & Sim & $\operatorname{Sim}$ & Não relaciona \\
\hline $\begin{array}{l}\text { A influência do consumo de } \\
\text { bebidas alcoólicas na ocorrência } \\
\text { de violência por parceiro íntimo: } \\
\text { revisão integrativa }\end{array}$ & Álcool & Uso & $\begin{array}{l}\text { Violência física, sexual, } \\
\text { psicológica, morale } \\
\text { patrimonial }\end{array}$ & Não & $\operatorname{Sim}$ & AD propicia Violência \\
\hline $\begin{array}{l}\text { Usuários de crackem tratamento } \\
\text { em Comunidades Terapêuticas: } \\
\text { perfil e prevalência }\end{array}$ & $\begin{array}{l}\text { Álcool, crack, } \\
\text { cocaína e tabaco }\end{array}$ & Dependência & $\begin{array}{l}\text { Violência física, sexual e } \\
\text { psicológica }\end{array}$ & Sim & Não & Causa e Efeito \\
\hline
\end{tabular}

Notas: AD: álcool e outras drogas; *Não discrimina qual droga foi utilizada, apenas descreve como outras drogas no geral, não ocorrendo distinção entre cocaína, maconha, crack, entre outras. ** Os termos "Causa" e "Efeito" foram utilizados de forma mais didática, pois se sabe que este tipo de análise só é possível de ser feita em estudos longitudinais, que não é o caso dos estudos aqui incluídos.

Fonte: Elaborado pelo autor (fev. 2019).

\section{CONSUMO DE ÁLCOOL E DE OUTRAS DROGAS E A VIOLÊNCIA CONTRA OIDOSO}

No Brasil, a violência contra o idoso se expressa das mais diversas formas. São frequentes as denúncias de abusos, preconceitos, maus tratos e negligências, além da violência física e sexual, somadas ao imaginário social que considera o idoso como decadente (BRASIL, 2014). Proporcionalmente ao aumento da expectativa de vida das pessoas (SILVA; DIAS, 2016), cresce, também, a violência intrafamiliar contra os idosos, gerando impacto importante na dimensão social e na saúde pública mundial.

Nesse contexto, em 2003, foi sancionada a Lei Federal n 1074, conhecida como Estatuto do Idoso, sendo estabelecidos os direitos das pessoas a partir de 60 anos, com previsão de punições aos que violarem tais direitos. A lei assegura que os filhos maiores de 18 anos sejam responsáveis pelo bem-estar e pela saúde de seus pais, proporcionando aos idosos uma vida com qualidade, livre de agressões de qualquer natureza, negligência e maus tratos (BRASIL, 2003).

No entanto, esta lei não foi suficiente para conter a violência contra o idoso e três artigos encontrados nesta revisão relacionaram a predominância da forma psicológica (verbal), agravada pelo uso do álcool, fator mais frequente associado à violência intrafamiliar (SILVA; DIAS, 2016; WITCZAK et al., 2016; WARMLING; LINDNER; COELHO,2017). Há um declínio da violência física e sexual com o envelhecimento, 
mas uma permanência importante da violência psicológica. Ademais, não se pode esquecer do abuso econômico como uma forma prevalente entre os idosos (WARMLING; LINDNER; COELHO, 2017).

Ressalta-seque a maior parte dos agressores são filhos ou cônjuges (WITCZAK et al., 2016), corroborando com o estudo feito por Brasil (2014), com maior risco se este familiar apresentar dependência de AD (SILVA; DIAS, 2016). Minayoetal.(2018) descrevem que em mais de 50\% dos lares que têm idosos e que os familiares são usuários de AD, esses idosos sofrem abuso físico ou emocional. Witczaketal.(2016) debatem que, nesses casos, o idoso encontra grande dificuldade de romper com o ciclo da violência, pois se vê dividido entre alguém que ama e que o maltrata, mas que, também, é uma fonte de ajuda.

Silva e Dias (2016) apontaramque o consumo de ADpelo idoso também seria uma causa dos conflitos familiares e, consequentemente, da violência. Em contrapartida, os autores debatem que esse consumo poderia ser uma estratégia para enfrentar a violência, atuando comoconsequência da violência.

O histórico de violência anterior também foi apontado nos estudos, ou seja, conviver em um contexto violento pode propiciar a reprodução de comportamentos agressivos contra os idosos, atuando como um ciclo de violência: quem foi agredido se torna agressor (SILVA; DIAS, 2016; MINAYOetal., 2018).

Uma limitação importante dos estudos é o fato de os idosos apontados serem independentes para as atividades da vida diária, fato que os fizeram procurar ajuda espontaneamente. Tal observação nos leva a questionar onde estariam os idosos dependentes de cuidado, aqueles restritos ao domicílio por complicações clínicas, neurológicas ou até mesmo da própria idade.

\section{CONSUMO DE ÁLCOOL E DE OUTRAS DROGAS E A VIOLÊNCIA CONTRA CRIANÇAS EADOLESCENTES}

Estudos mostram que a violência se inicia muito cedo na vida de algumas pessoas, podendo ser representada por ação ou omissão capaz de provocar danos, lesões e transtornos no desenvolvimento integral. Algumas crianças sentem-se abandonadas, sem importância, levando-as a acreditarem que não têm valor, e a adotarem o pensamento de que os conflitos podem ser resolvidos por meio da violência (BRASIL,2018).

A preocupação com os direitos das crianças e adolescentes é introduzida legalmente em 1990, com a aprovação do Estatuto da Criança e do Adolescente (ECA), que determina a proteção integral aos direitos dos cidadãos em desenvolvimento, atribuindo ao Estado o dever de garantir a promoção a este exercício, a fim de proporcionar direito à vida, saúde, educação, alimentação, ao esporte, lazer, à cultura, dignidade, ao respeito, à liberdade e, principalmente, ao convívio familiar e comunitário (BRASIL, 1990).

Os artigos com este grupo populacional debatem que a violência sofrida na infância e na adolescência acarreta maior chance de consumo de substâncias psicoativas na vida adulta, além de destacarem que a convivência com familiares adictos a AD aumenta não só o consumo dessas substâncias como, também, a vulnerabilidade e a violência intrafamiliar (SILVA; PADILHA, 2013; OLIVEIRA etal., 2016; FONTES; CONCEIÇÃO; MACHADO, 2017). Aconvivência na família com o consumo de álcool é internalizado e passa a fazer parte do cognitivo dessas crianças e adolescentes, podendo atuar de forma positiva ou negativa na formação do indivíduo, sendo um fator importante no surgimento do alcoolismo (SILVA; PADILHA, 2013). 
Outro ponto citado foi a associação do consumo de AD na adolescência com maior probabilidade de se envolverem em atos violentos, tanto como vítimas (COSTA etal., 2015; OLIVEIRA etal., 2016), tanto como autores (MOREIRA etal., 2013; SILVA; PADILHA, 2013; OLIVEIRA etal., 2016). O álcool pode interferir na perda de limites, precipitando o envolvimento com a violência, e funcionar como porta de entrada para outras drogas psicoativas. O adolescente é mais fragilizado, exposto e vulnerável ao uso dessas substâncias, além de ser mais influenciável pelos pares, estando mais suscetívela comportamentos impulsivos e de risco (BRASIL, 2018).

A experiência da violência intrafamiliar também foi citada como encorajadora de situações de violência psicológica (bullying) entre escolares, agravada pelo consumo de álcool pelos adolescentes (SILVA; PADILHA, 2013; OLIVEIRA etal., 2016; FONTES; CONCEIÇÃO; MACHADO, 2017). A família é o primeiro espaço de socialização do indivíduo, e a escola é outro importante espaço, devendo, portanto, fomentar discussões sobre violência, drogas, direitos e deveres de cada esfera governamental, de forma a garantir assistência adequada ao pleno desenvolvimento desses indivíduos.

Segundo a Pesquisa Nacional de Saúde do Escolar (PeNSE), em 2015, 55,5\% dos estudantes adolescentes já haviam consumido bebidas alcoólicas e 17\% já haviam experimentado drogas ilícitas. Quanto aos que consumiam na época da pesquisa, 7,4\% indicaram consumo de álcool e 4,2\% o uso de drogas ilícitas. A pesquisa descreveu, ainda, que 7,4\% já haviam sofrido violência psicológica (bullying) e outros 19,8\% já haviam praticado este tipo de violência (BRASIL, 2016a).

Os artigos com dados da PeNSEincluídos nesta revisão apontaram que o bullyingamplifica o consumo de $A D$, sendo tais substâncias fatores importantes na adoção de comportamentos de risco. Segundo os autores, as vítimas apresentaram mais chances de se envolverem com álcool e drogas; e o abuso sexual teve relação com o consumo de AD (OLIVEIRA etal., 2016; FONTES; CONCEIÇÃO; MACHADO, 2017).

\section{CONSUMO DE ÁLCOOL E DE OUTRAS DROGAS E A VIOLÊNCIA POR PARCEIRO ÍNTIMO E A VIOLÊNCIA CONTRA AS MULHERES}

A violência por parceiro íntimo é descrita como toda ou qualquer ação ou omissão direcionada a uma pessoa com a qual se tem uma relação íntima capaz de causar dano de ordem física, psicológica ou sexual (ARAÚjo etal., 2018). Quase sempre representa uma relação desproporcional para a questão de gênero, sendo a mulher a maior vítima, tanto pela questão cultural atribuída, pela história de dominação e poder, quanto pela questão física de força (SILVA; COELHO; NJAINE, 2014; LINDNERetal., 2015; ARAÚJO etal., 2018).

Segundo Reichenheimetal.(2011), nos conflitos que emergem no cotidiano dos casais, houve uma prevalência da violência psicológica $(78,3 \%)$, seguida do abuso físico menor $(21,5 \%)$ e dos abusos físicos graves (12,9\%). Tais achados também foram descritos por Andrade etal.(2016), os quais apontaram ocorrência de $98,4 \%$ de violência psicológica, seguida de $25,4 \%$ de violência física.

Os artigos que tratam dessa temática foram unânimes em enfatizar o papel do álcool como principal fator relacionado à violência por parceiro íntimo (SILVA; COELHO; NJAINE, 2014; ANDRADE etal., 2016; ARAÚJO etal., 2018), e, também, como agravante das lesões (LINDNERetal., 2015; ANDRADE etal., 2016). O estudo de Araújo etal. (2018) caracterizou o consumo alcoólico pelo agressor em $40 \%$ dos episódios violentos; 35\% no estudo de Andrade etal. (2016); e 18,5\% na pesquisa de Lindneretal. (2015). 
Apenas um estudo estabeleceu a relação da violência com o consumo de drogas, descrevendo que $20 \%$ dos agressores se consideraram usuários (ANDRADE etal., 2016). Outro resultado apontado pelos estudos é que os homens estudados responsabilizavam a mulher, atribuindo o ciúme como principal motivo. Em contrapartida, as mulheres atribuíam o consumo de AD como causa da violência, seguido do término da relação (SILVA; COELHO; NJAINE, 2014; LINDNERetal., 2015). O consumo de álcool pela vítima apareceu em um dos artigos, sendo consequência da violência, atuando como alívio da dor e do sofrimento. Por outro lado, esse consumo foi considerado como um fator que aumenta a chance de sofrer violência, pois pode gerar um desequilíbrio emocional nos cônjuges, com potencial de agravar os conflitos familiares (LINDNERetal., 2015).

No Brasil, em 2006, foi sancionada a Lei Maria da Penha (Lei n 11.340/2006), que constitui uma importante conquista e um recurso fundamental para o enfrentamento da violência contra a mulher (BRASIL, 2006b).

Estimativas globais indicam que uma em cada três mulheres (35\%) já sofreu algum tipo de violência por parceiro íntimo ou por terceiros durante a vida. Ainda, 38\% dos assassinatos de mulheres são cometidos por um parceiro masculino (OPAS, 2017). No Brasil, segundo dados do relatório global de 2019 da organização não governamental internacional HumansRightsWatch(HRW) [Observatório dos Direitos Humanos, em tradução livre], em 2016, 4.645 mulheres foram assassinadas, o que representa uma taxa de 4,5 homicídios para cada 100 mil brasileiras, caracterizando uma epidemia de violência doméstica no país (HRW, 2019). Quando se desagrega a população feminina pela variável raça/cor, a taxa de homicídios (por 100 mil) é maior entre as mulheres negras $(5,3)$ do que entre as não negras $(3,1)$. De 2006 a 2016, a taxa de homicídios para negras aumentou $15,4 \%$, enquanto que entre as não negras houve queda de $8 \%$. Tem-se, ainda, que as mulheres jovens são mais vitimadas do que as mais velhas (IPEA; FBSP, 2018).

A violência contra a mulher atinge todos os grupos femininos, independente de raça, cor, renda ou crença (SOUSA; NOGUEIRA; GRADIM, 2013); e, frequentemente, ocorre nos próprios domicílios(ROMAGNOLI, 2015; MOREIRA etal., 2015; BRASIL, 2015). Em relação ao agressor, o estudo feito por Silva etal. (2014) mostrou que o companheiro atual ou o ex foi responsável por $62,8 \%$ dos atos violentos. Já no estudo de Oliveira e Leal (2016), a proporção foi de $85 \%$. Esses dados reforçam aqueles encontrados pela pesquisa conduzida pelo Senado Federal, em 2015, a qual encontrou proporção igual a 73\% (BRASIL, 2015).

Por envolver questões afetivas, emocionais e financeiras importantes, verifica-se uma tendência de baixa notificação e providências, devido ao fato de a vítima se culpar pela violência sofrida, por esperar que o comportamento violento cesse, ou, ainda, por temer pela sua integridade física ou a de seus filhos, o que dificulta o rompimento da relação abusiva (SOUZA e SOUZA et al.,2015; SOUZA e SOUZA et al.,2016; SOUZA e SOUZA et al.,2017).

De acordo com os dados do Sistema de Informação de Agravos de Notificação (Sinan), em 2016, no âmbito dos serviços de saúde brasileiros, o registro de violência física foi predominante (55,5\%), seguido de violência psicológica $(27,9 \%)$ e violência sexual $(14,8 \%)$. No mesmo ano, o consolidado de registros de ocorrências policiais - Sistema Nacional de Informações de Segurança Pública, Prisional e sobre drogas do Ministério da Justiça-mostrou 63,6\% de registros de ameaça, 33,1\% de lesões corporais intencionais e 3,2\% de estupros, podendo considerar como violência psicológica, física e sexual, respectivamente. Tais dados apontam uma importante diferença quanto ao local de registro do fato violento, mostrando que nenhum indicador sozinho é capaz de demonstrar o real panorama da violência contra a mulher no Brasil, sendo cada um deles capaz de demonstrar a violência em situações e momentos distintos (BRASIL, 2016b). 
Destaca-se que quatro estudos se referiram à mulher no período gestacional, sendo que dois deles relacionaram o consumo de AD como principal fator de associação à violência, com consequência sobre a assistência pré-natal, pois as mulheres apresentaram baixa adesão às consultas, fato que impõe risco às gestantes e aos bebês (VIELLASetal., 2013; CARNEIRO etal., 2016). O artigo de Teixeira etal. (2015) apontou que cerca de $66,6 \%$ das gestantes que sofreram agressão já haviam sofrido violência na infância e presenciaram suas mães apanharem dos companheiros alcoolizados.

Cinco estudos apontaram as mulheres enquanto usuárias de AD, sendo que todos reportaram a violência como disparador do consumo de álcool e de outras drogas, além do uso aumentar as chances de se envolverem em atos violentos, tanto como vítimas e/ou comoautoras (ESPER et al., 2013; SOUZA et al., 2016; HAIEK et al., 2016; AGUIAR; MENEZES, 2017; LUCCHESE et al., 2017). Outro ponto descrito nos artigos é que as usuárias de AD, por vezes, sujeitam-se à prostituição e violência para adquirir a droga (SOUZA et al., 2016; HAIEK et al., 2016; AGUIAR; MENEZES, 2017), envolvendo-se em situações de conflito por disputa das substâncias. Assim, o consumo de AD pode estar relacionado como causa de violência em relação à vítima, demonstrando as prevalências de uso de AD pela vítima em 23,9\% (ALBUQUERQUE; SILVA, 2017); 21,4\% (AGUIAR; SILVA; MONTE, 2014); 23,6\% (LEITE et al., 2017).

Diante disso, sugere-se a relação entre o uso de AD como um importante fator para a violência contra a mulher, conforme aponta Brasil (2016b). Destaca-se que entre os estudos aqui analisados, Esper et al.(2013) apontaram que 25,7\% dos agressores estavam sob efeito de álcool; Romagnoli (2015) indicou que $73,6 \%$ dos agressores tinham problemas com álcool; Aguiar, Silva e Monte (2014) encontraram que $53,17 \%$ dos autores de crimes sexuais haviam usado AD; Moreira et al. (2015) apontaram que 57,1\% dos agressores estavam com suspeita de uso de álcool; Silva et al. (2015) constataram que 50,8\% dos agressores estavam sob o efeito de álcool e 46,1\% sob efeito de outras drogas. Complementando os dados citados, Viera et al. (2014) encontraram que em abusadores de AD, a taxa de agressão é 6,5 vezes mais alta, sendo essa informação um importante indício de que não se pode deixar de relacionar o consumo de AD com a violência intrafamiliar.

\section{CONSUMO DE ÁLCOOL E DE OUTRAS DROGAS E A VIOLÊNCIA ENTRE OS DEMAIS MEMBROS DAFAMÍLIA}

No presente levantamento, oito estudos relacionaram a violência intrafamiliar de forma global, não ressaltando nenhum grupo específico (BES et al., 2013; REIS; UCHIMURA; OLIVEIRA, 2013; SOARES et al., 2014; CARAVACA-MORERA; PADILHA, 2015; CLARO et al., 2015; SOUTO et al., 2017; MARTINS; NASCIMENTO, 2017; MADALENA; SARTES, 2018). Nestes artigos, foram descritos que a família não é a única causa do consumo de $A D$, mas um dos mais importantes fatores relacionados ao início e à manutenção do vício (SILVA; COELHO; NJAINE, 2014). Outros fatores como vulnerabilidade social, pobreza, falta de oportunidades na vida e de imposição de regras, entre outros motivos, podem acarretar o consumo de AD e, consequentemente, o aumento da violência intrafamiliar, tornando-se um ciclo vicioso.

Alguns estudos descreveram a ocorrência de violências contra homens, porém, não há discriminação específica na violência familiar, tratando-a de forma geral (CLARO et al., 2015; SOUTO et al., 2017; WARMLING; LINDNER; COELHO, 2017). Quandohá descrição de ocorrência no domicílio, a maior parte das vítimas são mulheres e crianças (BES et al., 2013; MARTINS; NASCIMENTO, 2017). 
Dois estudos realizados com dependentes de AD mostraram que as vítimas procuraram tratamento do vício por causa da violência sofrida na família (SOARES et al., 2014; CARAVACA-MORERA; PADILHA, 2015). Outro estudo relatou a violência intrafamiliar como causa de morar na rua e de ter iniciado o uso de AD, e ainda associou o uso de AD ao exemplo dado pelos familiares como motivador da iniciação (CARAVACAMORERA; PADILHA, 2015). Por último, o estudo de Claro et al. (2015) também relacionou o uso de AD com a presença de transtornos psiquiátricos, mostrando maior consumo quando diagnosticados com problemas mentais e, consequentemente, maior interação com a violência.

\section{CONSIDERAÇÕES FINAIS}

A análise dos estudos aqui incluídos permitiu investigar a interferência do consumo de AD na violência intrafamiliar, com seus diversos membros (mulheres, crianças, adolescentes, idosos) e sob vários aspectos, sugerindo que o álcool é a principal substância lícita mais envolvida no fenômeno da violência intrafamiliar no Brasil, assim como outras drogas ilícitas, mesmo que em menores proporções. Maior parte dos artigos indicou o uso de AD como um dos principais fatores (propiciador, influenciador, motivador, desencadeador) da violência. Em contrapartida, também foi descrito que o consumo de AD pode ser consequência da violência intrafamiliar, podendo atuar como um ciclo de consumo e reação, sendo a violência uma propulsora do uso e vice-versa, descrevendo o uso de álcool e de outras drogas como importante, mas não unicausal para a violência na família.

Apesar de a busca ter sido ampla, utilizando diversos descritores e estratégias, este estudo apresenta como limitação o fato de terem sido avaliados apenas estudos publicados em português. Mesmo com a possibilidade de a busca ter sido feita em outras bases, fazê-la apenas na Biblioteca Virtual em Saúde foi devido ao fato de que nela reúnem-se diversas bases brasileiras importantes, mantendo uma melhor logística do estudo, sem deixar de acessar artigos importantes.

A partir das pesquisas analisadas, questiona-se que o local do estudo tem grande importância no papel que o $A D$ ocupa nos casos de violência. Nos inquéritos realizados em estabelecimentos de segurança pública como delegacias, Ministério Público ou justiça criminal, o consumo de AD parece estabelecer maior lugar como causa da violência, visto que os autores de atos criminosos utilizam o consumo de $A D$ como justificativa para a violência. Em contrapartida, os artigos desenvolvidos em estabelecimentos de saúde, como Unidades de Saúde da Família, Hospitais, Centros de Referência, entre outros, o consumo de $A D$ está relacionado à violência como causa multifatorial, podendo atuar tanto como causa como consequência - ou ambas.

A maior parte dos estudos identificou a influência de outros fatores de risco importantes no contexto do $A D$, tais como desigualdade de gênero, escolaridade, condições socioeconômicas precárias, fraco apoio familiar, rede de apoio ineficiente, permissividade em relação à violência, história de violência na infância e isolamento social.

Outro ponto que merece destaque é a falta de padronização da utilização dos termos relacionados ao padrão de uso do álcool e das outras drogas, e a definição dos tipos de drogas analisados, fatos muito importantes, pois é preciso analisar se as diferenças entre os padrões (uso, abuso, ingestão, dependência, entre outros) e os tipos de drogas (lícitas e ilícitas) influenciam mais ou menos na ocorrência da violência na família. Ademais, isso dificulta a comparação entre os estudos, sendo um fator limitante, tornando- 
se de extrema relevância diferenciar os tipos e padrões de consumo das substâncias, pois nem toda experimentação ou dependência terá relação com a violência.

Apesar de os estudos qualitativos serem de extrema importância nas análises, principalmente nesta temática, já que as causas da violência são múltiplas, observou-se maior parte de estudos quantitativos, mas de cunho transversal. Assim, faz-se necessária a realização de estudos longitudinais, na tentativa de avaliar o nexo causal entre o consumo de álcool e de outras drogas e os atos violentos na família, devendo ser abordado de maneira complexa, dinâmica e contextualizada, diferenciando tipos de drogas e padrões de consumo.Além disso, sugere-se a realização de mais estudos voltados aos idosos, por terem sido encontrados em menor proporção, sendo ainda os que apresentaram menores discussões sobre o papel do $A D$ na violência. Apesar da maior parte dos estudos envolverem mulheres como vítimas dos atos violentos estimulados pelo consumo de $A D$, principalmente de seus parceiros íntimos, estimula-se a realização de mais estudos com este foco, devido ao grande impacto nas estatísticas de morbimortalidade feminina, apresentando-se como um desafio à abordagem dos profissionais de saúde e dos demais seguimentos dasociedade.

Reconhecendo esses dois fenômenos como complexos, multicausais e multifatoriais, com graves consequências econômicas, psicológicas e sociais na população, torna-se essencial considerá-los nas políticas públicas brasileiras, pois ocorrem simultaneamente e compartilham um conjunto complexo de fatores de risco, requerendo ações intersetoriais para seuenfrentamento.A abordagem a esses dois problemas deve ocorrer em todos os pontos da rede de atenção à saúde, nos diversos níveis de complexidade, buscando apoio e acompanhamento aos envolvidos em atos violentos, estando ou não sob o efeito de drogas. Essas iniciativas precisam estar apoiadas numa perspectiva de respeito à identidade e à cidadania dos sujeitos, acompanhadas de diversas modificações na sociedade, com maior incentivo à qualidade da educação, na melhoria das condições de trabalho, cultura, renda, lazer, e de vida.

\section{REFERÊNCIAS BIBLIOGRÁFICAS}

AGUIAR, C.M.D. de; MENEZES, J.de A. Vivências sexuais de mulheres jovens usuárias de crack. Barbarói, v.49, p.214-238, 2017. Disponível em: https://online.unisc.br/seer/index.php/barbaroi/article/view/8943. Acesso em: 18 fev. 2019.

AGUIAR, J.R.V. de; SILVA, G.M. e; MONTE, N.L. Estudo sobre a violência sexual em Serviço de Atendimento à Mulher. Revista de Enfermagem da UFPI, v.3, n.4, p.79-87, 2014. Disponível em: http://ojs.ufpi.br/ index.php/reufpi/article/view/3322/pdf. Acesso em: 18 fev. 2019.

ALBUQUERQUE, A.L. de; SILVA, W.C. da. Perfil da violência sexual contra mulheres atendidas no serviço de apoio à mulher. Revista de Enfermagem UFPE On Line,v.11, supl.5, p.2106-2115,2017.Disponívelem: https://periodicos.ufpe.br/revistas/revistaenfermagem/article/viewFile/23365/18994. Acesso em: 18 fev. 2019.

ANDRADE, R.F.V.; ARAúJO, M. A. L.; DOURADO, M. I. C.; MIRANDA, A. B. E.; REIS, C. B. da S. Prevalência e fatores associados à violência entre parceiros íntimos após a revelação do diagnóstico de doenças sexualmente transmissíveis ao parceiro. Cadernos de Saúde Pública, v.32, n.7, e00008715, 2016. Disponivel em: http://www.scielo.br/scielo.php?script=sci_arttext\&pid=S0102-311X2016000705007\&lng =en\&nrm=iso. Acessoem: 18 fev. 2019. 
ANDREUCCETTI, G.; CHERPITEL, C. J.; CARVALHO, H. B.;LEYTON, V.; MIZIARA, I. D.; MUNOZ, D. R.; REINGOLD, A. L.; LEMOS, N. P. Alcohol in combination with illicit drugs among fatal injuries in Sao Paulo, Brazil: an epidemiological study on the association between acute substance use and injury. Injury, v.49, ก.12, p.2186-2192, 2018.

ARAÚJO, W.S.C. de; SILVA, A. F. da; ESTRELA, F. M.; LÍRIO, J. G. dos S.; CRUZ, M. A. da; SANTOS, J. R. L. S.; PEREIRA, A. A influência do consumo de bebidas alcoólicas na ocorrência de violência por parceiro íntimo: revisão integrativa. Arquivos de Ciências da Saúde da UNIPAR, v.22, n.2, p.117-122, 2018. Disponível em: http://revistas.unipar.br/index.php/saude/article/view/6380. Acessoem: 18 fev. 2018.

BENNETT, L.; O'BRIEN, P. Effects of coordinated services for drug-abusing women who are victims of intimate partner violence. Violence Against Women, v.13, n.4, p.395-411, 2007.

BES, T.M.; LOPES, F. A. R.; MORGAN, G. J.; RIBEIRO, M. S.; DUARTE, W. R. Relação da violência intrafamiliar e o uso abusivo de álcool ou entorpecentes na cidade de Pelotas, RS. Revista AMRIGS, v.57, n.1, p. 9-13, mar. 2013. Disponível em: http://bases.bireme.br/cgi-bin/wxislind.exe/iah/online/?lsisScript=iah/iah. xis\&src=google\&base=LILACS\&lang=p\&nextAction=lnk\&exprSearch=686151\&indexSearch=ID. Acesso em: 18 fev. 2019.

BRASIL. Lei n 10.741 , de $1^{\circ}$ de outubro de 2003. Dispõe sobre o Estatuto do Idoso e dá outras providências. Brasília: Ministério dos Direitos Humanos, 2003 b.

BRASIL. Lei $n^{\circ}$ 11.340, de 7 de agosto de 2006. Cria mecanismos para coibir a violência doméstica e familiar contra a mulher, nos termos do $\S 8^{\circ}$ do art. 226 da Constituição Federal, da Convenção sobre a Eliminação de Todas as Formas de Discriminação contra as Mulheres e da Convenção Interamericana para Prevenir, Punir e Erradicar a Violência contra a Mulher; dispõe sobre a criação dos Juizados de Violência Doméstica e Familiar contra a Mulher; altera o Código de Processo Penal, o Código Penal e a Lei de Execução Penal; e dá outras providências. Brasília: Ministério dos Direitos Humanos, 2006b.

BRASIL. Lei n 11.343, de 23 de agosto de 2006. Institui o Sistema Nacional de Políticas Públicas sobre Drogas -Sisnad; prescreve medidas para prevenção do uso indevido, atenção e reinserção social de usuários e dependentes de drogas; estabelece normas para repressão à produção não autorizada e ao tráfico ilícito de drogas; define crimes e dá outras providências. Brasília: Ministério da Saúde, $2006 a$.

BRASIL. Ministério da Saúde. Secretaria de Gestão Estratégica e Participativa. Departamento de Monitoramento e Avaliação da Gestão do SUS. Temático prevenção de violência e cultura de paz III. Brasília: Organização Pan-Americana de Saúde, 2008.

BRASIL. Ministério da Saúde. Secretaria de Políticas de Saúde. Violência intrafamiliar: orientações para a prática em serviço. Cadernos de Atenção Básica No 8. Série A - Normas e Manuais Técnicos; n 131. Brasília: Ministério da Saúde, 2002.

BRASIL. Ministério da Saúde. Secretaria de Vigilância em Saúde. Departamento de Vigilância de Doenças e Agravos não Transmissíveis e Promoção da Saúde. Vigitel Brasil 2018: vigilância de fatores de risco e proteção para doenças crônicas por inquérito telefônico: estimativas sobre frequência e distribuição sociodemográfica de fatores de risco e proteção para doenças crônicas nas capitais dos 26 Estados brasileiros e no Distrito Federal em 2018. Brasília: Ministério da Saúde, 2019.

BRASIL. Ministério da Saúde. Secretaria Executiva. Coordenação Nacional de DST/Aids. A Política do Ministério da Saúde para atenção integral a usuários de álcool e outras drogas. Ministério da Saúde, Secretaria Executiva, Coordenação Nacional de DST e Aids. Brasília: Ministério da Saúde, $2003 a$. 
BRASIL. Ministério dos Direitos Humanos. Lei n 8.069, de 13 de julho de 1990. Dispõe sobre o Estatuto da Criança e do Adolescente e dá outras providências. Brasília: Ministério dos Direitos Humanos, 1990.

BRASIL. Ministério dos Direitos Humanos. Secretaria Nacional de Proteção dos Direitos da Criança e Adolescente. Violência contra Crianças e Adolescentes: Análise de Cenários e Propostas de Políticas Públicas. Elaboração de Marcia Teresinha Moreschi. Brasília: Ministério dos Direitos Humanos, 2018. Disponível em: https://www.mdh.gov.br/biblioteca/consultorias/conada/violencia-contra-criancas-eadolescentes-analise-de-cenarios-e-propostas-de-politicas-publicas.pdf. Acesso em: 20 maio. 2019.

BRASIL. Observatório da Mulher contra a Violência. Panorama da violência contra as mulheres no Brasil: indicadores nacionais e estaduais. Brasília: Senado Federal, 2016b. Disponível em: http://www2.senado. leg.br/bdsf/item/id/529424. Acesso em: 20 maio 2019.

BRASIL. Pesquisa nacional de saúde do escolar: 2015. Instituto Brasileiro de Geografia e Estatística IBGE, Coordenação de População e Indicadores Sociais. Rio de Janeiro: IBGE, 2016a.

BRASIL. Secretaria de Direitos Humanos da Presidência da República. Brasil: manual de enfrentamento à violência contra a pessoa idosa. É possível prevenir. É necessário superar. Texto de Maria Cecília de Souza Minayo. Brasília, DF: Secretaria de Direitos Humanos da Presidência da República, 2014.

BRASIL. Senado Federal. Violência doméstica e familiar contra a mulher. Coordenação de Controle Social, Serviço de Pesquisa DataSenado. Brasília: Senado Federal, 2015. Disponível em: https://www12. senado.leg.br/institucional/omv/entenda-a-violencia/relatorios/pesquisa-datasenado-2015-relatorio-etabelas-descritivas. Acesso em: 18 fev. 2019.

CARAVACA-MORERA, J.A.; PADILHA, M.I. A dinâmica das relações familiares de moradores de rua usuários de crack. Saúde em Debate, v.39, n.106, p.748-759, 2015. Disponível em: http://www.scielo.br/scielo. php?script=sci_arttext\&pid=S0103-11042015000300748\&lng=en\&nrm=iso. Acesso em: 18 fev. 2019.

CARNEIRO, J.F.; VALONGUEIRO, S.; LUDERMIR, A. B.; ARAÚJO, T. V. B. de. Violência física pelo parceiro íntimo e uso inadequado do pré-natal entre mulheres do Nordeste do Brasil. Revista Brasileira de Epidemiologia, v.19, n.2, p.243-255, 2016. Disponível em: http://www.scielo.br/scielo.php?pid=S1415790X2016000200243\&script=sci_abstract\&tlng=pt. Acesso em: 18 fev. 2019.

CLARO, H. G.; OlIVEIRA, M. A. F. de; TITUS, J. C.; FERNANDES, I. F. de A. L.; PINHO, P. H.; TARIFA, R. R. Uso de drogas, saúde mental e problemas relacionados ao crime e à violência: estudo transversal. Revista Latino-Americana de Enfermagem, v.23, n.6, p.1173-1180, 2015. Disponível em:http://www.scielo.br/ scielo.php?script=sci_arttext\&pid=S0104-11692015000601173\&lng=pt\&nrm=iso. Acesso em: 18 fev. 2019.

COSTA, A.P.S. da; OLIVEIRA, D. A. de; RODRIGUES, M. P.; FERREIRA, M. A. F. Violência doméstica e abuso de álcool e drogas na adolescência. Revista Ciência Plural, v.1, n.2, p.48-56, 2015. Disponível em: https:// periodicos.ufrn.br/rcp/article/view/7616. Acesso em: 21 maio 2019.

DAHLBERG, L.; KRUG, E. Violência:Um problema global de saúde pública. Ciência \& Saúde Coletiva, v.11, Supl. 1, p.1163-1178, 2006. Disponível em: https://www.scielo.br/j/csc/a/jGnr6ZsLtwkhvdkrdfhpcdw/?lang=PT. Acesso em: 18 fev. 2019.

ESPER, L.H.; CORRADI-WEBSTER, C. M.; CARVALHO, A. M. P.; FURTADO, E. F. Mulheres em tratamento ambulatorial por abuso de álcool: características sociodemográficas e clínicas. Revista Gaúcha de Enfermagem, v.34, n.2, p.93-101, 2013. Disponível em: http://www.scielo.br/scielo.php?script=sci_ arttext\&pid=S1983-14472013000200012\&lng=en\&nrm=iso. Acesso em: 18 fev. 2019. 
FONTES, L.F.C.; CONCEIÇÃO, O.C.; MACHADO, S. Violência sexual na adolescência, perfil da vítima e impactos sobre a saúde mental. Ciência \& Saúde Coletiva, v.22, n.9, p.2919-2928, 2017. Disponível em: http://www.scielo.br/scielo.php?script=sci_arttext\&pid=S1413-81232017002902919\&lng=pt\&nrm=iso. Acesso em: 18 fev. 2019.

FREITAS, N.A.; SILVA, A.V.S; BRASIL, A.C.O.; BASTOS, V.P.D; FERNANDES, L.C.B.C. Perfil clínicoepidemiológico de adolescentes e jovens vítimas de ferimento por arma de fogo. Cadernos Saúde Coletiva, v.25, n.4, p.429-435, 2017. Disponível em: https://www.scielo.br/j/cadsc/a/ C5x8CWHv3fdNVZCzqbJS7sL/?format=pdf\&lang=pt. Acesso em: 18 fev. 2019.

GBD - GLOBAL BURDEN OF DISEASES. Alcohol use and burden for 195 countries and territories, 19902016: a systematic analysis for the Global Burden of Disease Study 2016. The Lancet, v.392, n.10152, p.1015-1035, 2018.

GeBARA, C.F.de P.; FERRI, C. P.; LOURENÇO, L. M.; VIEIRA, M. de T.; BHONA, F. M. de C.; NOTO, A. R. Patterns of domestic violence and alcohol consumption among women and the effectiveness of a brief intervention in a household setting: a protocol study. BMC Womens Health, v.15, p.78, 2015.

GOMES SATO SGOBERO, J.K.; LORENNA VICCENTINE COUTINHO MONTESCHIO, L.V.C.; ZURITA, R.C.M.; OLIVEIRA, R.R.; MATHIAS, T.A.F. Violência física por parceiro íntimo na gestação: prevalência e alguns fatores associados. Aquichan, v.15, n.3, p.339-350, 2015. Disponível em: http://www.scielo.org.co/scielo. php?pid=S1657-59972015000300003\&script=sci_abstract\&tlng=pt. Acesso em: 18 fev. 2019.

GRAHAM, K.;BERNARDS, S.; WILSNACK, S. C.; GMEL, G. Alcohol may not cause partner violence but it seems to make it worse: a cross-national comparison of the relationship between alcohol and severity of partner violence. Journal of Interpersonal Violence, v.26, n.8, p.1503-1523, 2011.

HAIEK, R.de C.; MARTIN, D.; ROCHA, F. C. M.; RAMIRO, F. de S.; SILVEIRA, D. X. da.Uso de drogas injetáveis entre mulheres na Região Metropolitana de Santos, São Paulo, Brasil. Physis: Revista de Saúde Coletiva, v.26, n.3, p.917-937, 2016. Disponível em: http://www.scielo.br/scielo.php?script=sci_arttext\&pid=S010373312016000300917\&lng=en\&nrm=iso. Acessoem: 18 fev. 2019.

HRW - HUMANS RIGHTS WATCH.World Report 2019-Events of 2018. United States of America: HRW, 2019. Disponível em: https://www.hrw.org/sites/default/files/world_report_download/hrw_world_ report_2019.pdf. Acesso em: 29 mar. 2019.

INCA - INSTITUTO NACIONAL DE CÂNCER JOSÉ ALENCAR GOMES DA SILVA. Vigitel 2017 e Estimativa de Consumo de Cigarros Ilícitos no Brasil. Divisão de Pesquisa Populacional. Secretaria Executiva da Comissão Nacional para Implementação da Convenção-Quadro para o Controle do Tabaco (SE-CONICQ). Rio de Janeiro: Ministério da Saúde, 2017. Disponível em: https://www.inca.gov.br/sites/ufu.sti.inca.local/ files//media/document//vigitel-2017-estimativa-de-consumo-de-cigarros-ilicitos-no-brasil.pdf. Acesso em: 20 maio 2019.

IPEA - INSTITUTO DE PESQUISA ECONÔMICA APLICADA; FBSP - FÓRUM BRASILEIRO DE SEGURANÇA PÚBLICA. Atlas da Violência 2018. Rio de Janeiro: Ipea/FBSP, jun. 2018.

LARANJEIRA, R.; DUAILIBI, S.M.; PINSKY, I. Álcool e violência: a psiquiatria e a saúde pública. Revista Brasileira de Psiquiatria, v.27, n.3, p.176-177, 2005.

LEITE, F.M.C.; AMORIM, M. H. C.; WEHRMEISTER, F. C.; GIGANTE, D. P. Violência contra a mulher em Vitória, Espírito Santo, Brasil. Revista de Saúde Pública, v.51, n.33, 2017. Disponível em:http://www.scielo.br/scielo. php?script=sci_arttext\&pid=S0034-89102017000100223\&lng=pt\&nrm=iso. Acessoem: 18 fev. 2019. 
LEONARD, K.E. Alcohol and intimate partner violence: when can we say that heavy drinking is a contributing cause of violence?. Addiction, v.100, n.4, p.422-425, 2005.

LINDNER, S.R.; COELHO, E. B. S.; BOLSONI, C. C.; ROJAS, P. F.; BOING, A. F. Prevalência de violência física por parceiro íntimo em homens e mulheres de Florianópolis, Santa Catarina, Brasil: estudo de base populacional. Cadernos de Saúde Pública, v.31, n.4, p.815-826, 2015. Disponível em: http://www.scielo. br/scielo.php?pid=S0102-311X2015000400815\&script=sci_abstract\&tlng=pt. Acesso em: 18 fev. 2019.

LIRA, M.O.S.C.; RODRIGUES, V.P.; RODRIGUES, A.D.; COUTO, T.M.; GOMES, N.P.; DINIZ, N.M.F. Abuso sexual na infância e suas repercussões na vida adulta. Texto \& Contexto Enfermagem, v.26, n.3, p.e0080016, 2017. Disponivel em: https://www.scielo.br/j/tce/a/Fq8Cg6F7bcbZRNhxFqKTMTR/?format=pdf\&lang=pt. Acesso em: 18 fev. 2019.

LUCCHESE, R.; CAIXETA F. de C.; SILVA, Y. V.; VERA, I.; FELIPE, R. L. de; CASTRO, P. A. de. Histórico de violência contra a mulher que vivencia o abuso de álcool e drogas. Revista de Enfermagem UFPE On Line, v. 11, supl.9, p.3623-3631, set. 2017. Disponível em: https://periodicos.ufpe.br/revistas/revistaenfermagem/ article/view/234505/27717. Acesso em: 18 fev. 2019.

MACHADO, J. C.; RODRIGUES, V. P.; VILELA, A. B. A.; SIMÕES, A. V.; MORAIS, R. L. G. L.; ROCHA, E. N. Violência intrafamiliar e as estratégias de atuação da equipe de Saúde da Família. Saúde e Sociedade, v.23, п.3, p.828-840, 2014.

MADALENA, T.S.; SARTES, L.M.A. Usuários de crack em tratamento em Comunidades Terapêuticas: perfil e prevalência. Arquivos Brasileiros de Psicologia, v.70, n.1, p.21-36, 2018. Disponível em:http://pepsic. bvsalud.org/scielo.php?script=sci_arttext\&pid=S1809-52672018000100003\&lng=pt\&nrm=iso. Acesso em: 18 fev. 2019.

MARTINS, A.G.; NASCIMENTO, A.R.A. do. Violência doméstica, álcool e outros fatores associados: uma análise bibliométrica.Arquivos Brasileiros de Psicologia, v.69,n.1,p.107-121, 2017. Disponível em:http:// pepsic.bvsalud.org/scielo.php?script=sci_arttext\&pid=S1809-52672017000100009\&lng=pt\&nrm=iso. Acesso em: 18 fev. 2019.

MENDES, K.D.S.; SILVEIRA, R.C.de C.P.; GALVÃO, C.M. Revisão integrativa: método de pesquisa para a incorporação de evidências na saúde e na enfermagem. Texto \& Contexto Enfermagem, Florianópolis, v.17, n.4, p.758-764, 2008. Disponível em: http://www.scielo.br/scielo.php?script=sci_arttext\&pid=S010407072008000400018\&lng=en\&nrm=iso. Acesso em: 20 maio 2019.

MINAYO, M.C.de S.; SOUZA, E. R. de; SILVA, M. M. A. da; ASSIS, S. G. de. Institucionalização do tema da violência no SUS: avanços e desafios. Ciência \& Saúde Coletiva, v.23, n.6, p.2007-2016, 2018.

MOREIRA, D.P.; VIEIRA, L. J. E. de S.; PORDEUS, A. M. J.; LIRA, S. V. G.; LUNA, G. L. M.; SILVA, J. G. e; MACHADO, M. de F. A. S. Exposição à violência entre adolescentes de uma comunidade de baixa renda no Nordeste do Brasil. Ciência \& Saúde Coletiva, v.18,n.5, p.1273-1282, 2013. Disponível em: http://www.scielo.br/scielo. php?pid=S1413-81232013000500012\&script=sci_abstract\&tlng=pt. Acesso em: 18 fev. 2019.

MOREIRA, G.A.R.; SOARES, P. S.; FARIAS, F. N. R.; VIEIRA, L. J. E. de S. Notificações de violência sexual contra a mulher no Brasil. Revista Brasileira em Promoção da Saúde, v.28, n.3, p.327-336, 2015. Disponível em: https://periodicos.unifor.br/RBPS/article/view/3877. Acesso em: 18 fev. 2019.

MOREIRA, T.C.; BELMONTE, E. L.; VIEIRA, F. R.; NOTO, A. R.; FERIGOLO, M.; BARROS, H. M. T. Community violence and alcohol abuse among adolescents: a sex comparison. Jornal de Pediatria, v.84, n.3, p.244250, 2008. 
OLIVEIRA, L.A.S. de; LEAL, S.M.C. Mulheres em situação de violência que buscaram apoio no centro de referência GenyLehnen/RS. Enfermagem em Foco, v.7, n.2, p. 78-82, 2016. Disponível em: http://revista. cofen.gov.br/index.php/enfermagem/article/view/800. Acesso em: 18 fev. 2019.

OlIVEIRA, W.A. de; SILVA, M. A. I.; SILVA, J. L. da; MELLO, F. C. M. de; PRADO, R. R. do; MALTA, D. C. Associações entre a prática de bullying e variáveis individuais e de contexto na perspectiva dos agressores. Jornal de Pediatria, v.92, n.1, p.32-39, 2016. Disponível em: http://www.scielo.br/scielo.php?script=sci_ arttext\&pid=S0021-75572016000100032\&lng=en\&nrm=iso. Acesso em: 18 fev. 2019.

OMS - ORGANIZAÇÃO MUNDIAL DA SAÚDE. Global report on trends in prevalence of tobacco smoking 2000-2025.2 ed. OMS, $2018 \mathrm{~b}$.

OMS - ORGANIZAÇÃO MUNDIAL DA SAÚDE. Global status reportonalcoholandhealth 2018. OMS, 2018 a. OMS - ORGANIZAÇÃO MUNDIAL DA SAÚDE. Preventing violence by reducing the availability and harmful use of alcohol. OMS, 2009. [Series of briefings on violenceprevention: theevidence].

OMS - ORGANIZAÇÃO MUNDIAL DA SAÚDE. World health statistics 2017: monitoring health for the SDGs, sustainable development goals. OMS, 2017.

OPAS - ORGANIZAÇÃO PAN-AMERICANA DA SAÚDE. Folha informativa- Violência contra as mulheres. OPAS, Brasil, 2017. Disponível em: https://www.paho.org/bra/index.php?option=com_content\&view=arti cle\&id=5669:folha-informativa-violencia-contra-as-mulheres\&ltemid=820. Acesso em: 29 mar. 2019.

ORGANIZAÇÃO MUNDIAL DASAÚDE - OMS. Version of the Introduction to the World Report on Violence and Health.Genebra: OMS; 2002. Disponivel em: https://www.who.int/violence_injury_prevention/ violence/world_report/en/introduction.pdf. Acesso em: 18 fev. 2019.

REICHENHEIM, M.E.; SOUZA, E. R. de; MORAES, C. L.; JORGE, M. H. P. de M.; SILVA, C. M. F. P. da; MINAYO, M. C. de S. Violência e lesões no Brasil: efeitos, avanços alcançados e desafios futuros. The Lancet, p.7589, 2011. Disponível em: https://www.thelancet.com/pb/assets/raw/Lancet//pdfs/brazil/brazilpor5.pdf. Acesso em: 16 fev. 2019.

REIS, L.M. dos; UCHIMURA, T.T.; OLIVEIRA, M.L.F. de. Perfil socioeconômico e demográfico em uma comunidade vulnerável ao uso de drogas de abuso. Acta Paulista de Enfermagem, v.26, n.3, p. 276-282,2013. Disponivel em: http://www.scielo.br/scielo.php?script=sci_arttext\&pid=S0103-21002013000300012\&lng =en\&nrm=iso. Acesso em: 18 fev. 2019.

ROMAGNOLI, R.C. A violência contra a mulher em Montes Claros. Barbarói, v.43, p.27-47, 2015. Disponível em: https://online.unisc.br/seer/index.php/barbaroi/article/view/4815. Acesso em: 18 fev. 2019.

SAMPAIO, R.F.; MANCINI, M.C. Estudos de revisão sistemática: um guia para síntese criteriosa da evidência científica. Revista Brasileira de Fisioterapia, v.11, n.1, p.83-89, 2007.

SANTOS, C. M. da C.; PIMENTA, C. A. de M.; NOBRE, M.R. C. A estratégia PICO para a construção da pergunta de pesquisa e busca de evidências. Revista Latino-Americana deEnfermagem, v.15, n.3, p.508-511, 2007.

SILVA JUNIOR, F.J.G. da; TOLENTINO, E.S.; OLIVEIRA, A.K.S.; MONTEIRO, C.F.S. Dependência química e violência no universo feminino: revisão integrativa. Revista de Pesquisa Cuidado é Fundamental Online, v.8, n.3, p.4681-4688, 2016. Disponível em: http://www.seer.unirio.br/cuidadofundamental/article/ view/4274. Acesso em: 18 fe. 2019. 
SILVA, A.C.L.G. da; COELHO, E.B.S.; NJAINE, K. Violência conjugal: as controvérsias no relato dos parceiros íntimos em inquéritos policiais. Ciência \& Saúde Coletiva, v.19, n.4, p.1255-1262, 2014. Disponível em: https://doi.org/10.1590/1413-81232014194.01202013. Acesso em: 18 fev. 2019.

SILVA, C.D.; GOMES, V. L. de O.; MOTA, M. S.; GOMES, G. C.; AMARIJO, C. L. Violência contra a mulher: agressores usuários de drogas ilícitas. Revista de Pesquisa Cuidado é Fundamental Online, v.7, n.2, p.2494-2504, 2015. Disponível em: https://www.redalyc.org/pdf/5057/505750946026.pdf. Acesso em: 18 fev. 2019.

SILVA, C.F.S.; DIAS, C.M. de S.B. Violência contra idosos na família: motivações, sentimentos e necessidades do agressor. Psicologia: Ciência e Profissão, v.36, n.3, p.637-652, jul./set. 2016. Disponível em: http:// www.scielo.br/pdf/pcp/v36n3/1982-3703-pcp-36-3-0637.pdf. Acesso em: 18 fev. 2019.

SILVA, S.É.D. da; PADILHA, M.I. O alcoolismo na história de vida de adolescentes: uma análise à luz das representações sociais. Texto \& Contexto Enfermagem, v.22, n.3, p.576-584, 2013. Disponível em: http:// www.scielo.br/scielo.php?script=sci_arttext\&pid=S0104-07072013000300002\&lng=en\&nrm=iso. Acesso em: 18 fev. 2019.

SILVEIRA, D.X.; DOERING-SILVEIRA, E.B. Padrões de uso de drogas: eixo, políticas e fundamentos. SenadSecretaria Nacional de Políticas sobre Drogas. Brasília: Ministério da Saúde, 2017.

SOARES, J.R.; FARIAS, S. N. P. de; DONATO, M.; MAURO, M. Y. C.; ARAÚJO, E. F. dos S.; GHELMAN, L. G. A importância da família no processo de prevenção da recaída no alcoolismo. Revista de Enfermagem da UERJ, v.22, n.3, p.341-346, 2014. Disponível em: https://www.e-publicacoes.uerj.br/index.php/ enfermagemuerj/article/view/13691. Acesso em: 18 fev. 2019.

SOUSA, A.K.A. de; NOGUEIRA, D.A.; GRADIM, C.V.C. Perfil da violência doméstica e familiar contra a mulher em um município de Minas Gerais, Brasil.Cadernos Saúde Coletiva, v.21,n.4,p.425-431, 2013. Disponível em: http://www.scielo.br/scielo.php?script=sci_arttext\&pid=S1414-462X2013000400011\&lng=en\&nrm=i so. Acesso em: 18 fev. 2019.

SOUTO, R.M.C.V.; BARUFALDI, L. A.; NICO, L. S.; FREITAS, M. G. de. Perfil epidemiológico do atendimento por violência nos serviços públicos de urgência e emergência em capitais brasileiras, Viva 2014. Ciência \& Saúde Coletiva, v.22, n.9, p.2811-2823,2017. Disponível em:http://www.scielo.br/scielo.php?script=sci_ arttext\&pid=S1413-81232017002902811\&lng=pt\&nrm=iso. Acesso em: 18 fev. 2019.

SOUZA e SOUZA, L.P.; COELHO, D. M. P.; SOUZA, A. G. de; RUAS, F. R. B.; FIGUEIREDO, T.; ALCÂNTARA, D. D. F.; SILVA, C. S. de O. "Em briga de marido e mulher, não se mete a colher?" Análise da violência baseado no gênero e o papel do setor saúde. Revista Eletrônica Gestão \& Saúde, v.6, n.1, p.79-94, 2015. Disponível em: http://periodicos.unb.br/index.php/rgs/article/view/2529. Acesso em: 20 maio. 2019.

SOUZA e SOUZA, L.P.; RUAS, R. F. B.; BRITO, M. F. S. F.; LEITE, M. T. de S.; SOARES, S. M. "Café \& prosa com as Marias": avaliação das mulheres sobre grupos operativos no manejo da violência de gênero. Revista de Educação Popular, v.16, n.1, p.92-103, jun. 2017.

SOUZA e SOUZA, L.P.; SOUZA, A. G. de; FIGUEIREDO, T.; BRITO, M. F. S. F.; LEITE, M. T. S.; SOUZA, K. V. de.Violência de Gênero: o silêncio e enfrentamento vivido pelas mulheres à luz da fenomenologia social. Revista de EnfermagemUFPEOn Line,v.10, n.10, p.3842-3850, 2016. Disponivel em: https://periodicos. ufpe.br/revistas/revistaenfermagem/article/download/11451/13271. Acesso em: 20 maio 2019. 
SOUZA, M. R.R. de; OLIVEIRA, J. F. de; CHAGAS, M. C. G.; CARVALHO, E. S. de S. Gênero, violência e viver na rua: vivências de mulheres que fazem uso problemático de drogas.Revista Gaúcha de Enfermagem, v.37,n.3,e59876,2016. Disponível em:http://www.scielo.br/scielo.php?script=sci_arttext\&pid=S198314472016000300418\&lng=pt\&nrm=iso. Acesso em: 18 fev. 2019.

SOUZA, M.T. de; SILVA, M.D. da; CARVALHO, R. de. Revisão integrativa: o que é e como fazer. Einstein, São Paulo, v.8, n.1, p.102-106, 2010. Disponível em: http://www.scielo.br/pdf/eins/v8n1/pt_1679-4508eins-8-1-0102.pdf. Acesso em: 20 maio 2019.

TEIXEIRA, S.V.B.; MOURA, M. A. V.; SILVA, L. R. da; QUeIROZ, A. B. A.; SOUZA, K. V. de; NETTO, L. A. Violência perpetrada por parceiro íntimo à gestante: o ambiente à luz da teoria de Levine.Revista da Escola de Enfermagem da USP, v.49,n.6,p.882-889, 2015. Disponível em: http://www.scielo.br/scielo. php?script=sci_arttext\&pid=S0080-62342015000600882\&lng=en\&nrm=iso. Acessoem: 18 fev. 2019.

TUMWESIGYE, N.M.; KYOMUHENDO, G. B.; GREENFIELD, T. K.; WANYENSE, R. K. Problem drinking and physical intimate partner violence against women: evidence from a national survey in Uganda. BMC Public Health, v.12, artigo 399, 2012.

VIEIRA, L.B.; CORTES, L. F.; PADOIN, S. M. de M.; SOUZA, I. E. de O.; PAULA, C. C. de; TERRA, M. G. Abuso de álcool e drogas e violência contra as mulheres: denúncias de vividos.Revista Brasileira de Enfermagem, v.67,n.3,p.366-372, 2014. Disponível em: http://www.scielo.br/scielo.php?script=sci_arttext\&pid=S003471672014000300366\&lng=en\&nrm=iso. Acesso em: 18 fev. 2019.

VIELLAS, E.F.; GAMA, S. G. N. da; CARVALHO, M. L. de; PINTO, L. W. Fatores associados à agressão física em gestantes e os desfechos negativos no recém-nascido. Jornal de Pediatria, v.89, n.1, p.83-90, 2013. Disponivel em: http://www.scielo.br/scielo.php?pid=S0021-75572013000100013\&script=sci_ abstract\&tlng=pt. Acesso em: 18 fev. 2019.

WARMLING, D.; LINDNER S.R.; COELHO E.B.S. Prevalência de violência por parceiro íntimo em idosos e fatores associados: revisão sistemática. Ciência \& Saúde Coletiva, v.22, n.9, p.3111-3125, 2017. Disponível em: http://www.scielo.br/pdf/csc/v22n9/1413-8123-csc-22-09-3111.pdf. Acesso em: 18 fev. 2019.

WITCZAK, I.V.; ACOSTA, M. A. F.; COUTINHO, R. X.; LEITE, M. T. Perdoar verdadeiramente ou agredir novamente: dilemas da violência familiar contra idosos. Revista Kairós Gerontologia, v.19, n.1, p.211225, 2016. Disponível em: https://revistas.pucsp.br/index.php/kairos/article/view/30055. Acesso em: 18 fev. 2019. 
Ocorrência de violência intrafamiliar relacionada ao consumo de álcool e outras drogas no Brasil

Grazielle Neves Soares, Marconi Moura Fernandes, Aline Maria Figueiredo Ko da Cunha e Luís Paulo Souza e Souza 